\title{
Secular trends in ocean tides: Observations and model results
}

\author{
M. Müller, ${ }^{1}$ B. K. Arbic, ${ }^{2,3}$ and J. X. Mitrovica ${ }^{4}$ \\ Received 18 May 2010; revised 8 February 2011; accepted 4 March 2011; published 21 May 2011.
}

[1] During the last century the response of the oceans to tidal forces has changed significantly. This study focuses on an analysis of long-term sea level records located in the Atlantic and Pacific, primarily in the Northern Hemisphere. It shows that changes of tidal amplitude and/or phase have taken place over large scales. The principal solar semidiurnal $\left(S_{2}\right)$ tide shows the largest trends. At some locations, the change in the mean tidal range due to tidal trends is significant compared with the trend in mean sea level. Thus, it might be advisable to consider these changes in studies of the impact of rising sea level. Numerical simulations of the principal lunar semidiurnal tide $\left(M_{2}\right)$ demonstrate a model sensitivity in the North Atlantic to changes in glacial isostatic adjustment and sea level rise, which captures $30-40 \%$ of the magnitude of the trends in observations. However, the spatial patterns do not agree well with those inferred from observations, suggesting that forward global models are currently useful for qualitative but not quantitative understanding of the observed trends. A global free oscillation synthesis indicates that sea level rise due to glacial isostatic adjustment leads to decreasing global resonant periods and increasing damping in the system and a coupled oscillator model shows that changes in sea level on the shelf are much more effective at perturbing shelf and ocean tides than sea level changes in the deep ocean.

Citation: Müller, M., B. K. Arbic, and J. X. Mitrovica (2011), Secular trends in ocean tides: Observations and model results, J. Geophys. Res., 116, C05013, doi:10.1029/2010JC006387.

\section{Introduction}

[2] During the past hundreds of millions of years the global pattern of tides and associated tidal dissipation have changed dramatically with the evolution of ocean basins and continents [Brosche and Sündermann, 1978]. These changes were primarily induced by the reconfiguration of ocean basins and the accompanied changes in geometry of the basin. On shorter time scales, i.e., in the last 20,000 years since the last glacial maximum, a large-scale modification of the tidal response of the ocean has also occurred. This modification was caused mainly by the deglaciation-induced (global average $\sim-130 \mathrm{~m}$ ) change in sea level, which led to significant changes in the extent and depth of the continental shelves [see Arbic and Garrett, 2010 and references therein].

[3] Previous studies of sea level records spanning the last 50-200 years show that ocean tides are still changing with surprisingly high rates; in some areas the change in amplitude

\footnotetext{
${ }^{1}$ School of Earth and Ocean Sciences, University of Victoria, Victoria, British Columbia, Canada.

${ }^{2}$ Department of Oceanography and Center for Ocean-Atmospheric Prediction Studies, Florida State University, Tallahassee, Florida, USA.

${ }^{3}$ Department of Geological Sciences, University of Michigan, Ann Arbor, Michigan, USA.

${ }^{4}$ Department of Earth and Planetary Sciences, Harvard University, Cambridge, Massachusetts, USA.
}

Copyright 2011 by the American Geophysical Union. 0148-0227/11/2010JC006387 exceeds $10 \%$ century $^{-1}$. One of the oldest sea level records usable for tidal analysis, a 1761 record by Maskelyne [1762] on the island of St. Helena in the South Atlantic, was analyzed by Cartwright [1971]. Specifically, he compared this record with data from 1969 and, although the lengths of the data sets are short ( $\sim 40$ days), he pointed out a trend in the diurnal tidal phase of $\sim 5^{\circ}$ century $^{-1}$. In contrast, no changes in the diurnal amplitude and the semidiurnal amplitudes and phases were detected. Cartwright [1971] assumed that these changes were either due to climatic changes during the little ice age, e.g., varying polar ice boundaries and increasing mean sea level, or due to changes in the internal wave field induced by perturbations in the thermocline structure of the ocean. Indeed, at Honolulu, Hawaii the secular trend of the $M_{2}$ amplitude has been attributed to changes in the stratification of the ocean [Colosi and Munk, 2006]. There, the $M_{2}$ amplitude has increased by $\sim 1 \mathrm{~cm}$ in the last 100 years; Colosi and Munk [2006] suggested that this increase is caused by a change in phase of the internal tide, which is generated nearby and propagates to the tide gauge station. Since the vector sum of internal plus barotropic tides is measured at the sea surface, the change in phase of the internal tide, leads to an amplitude and phase change in the total tide.

[4] Further studies [Cartwright, 1974; Woodworth et al., 1991; Flick et al., 2003; Ray, 2006, 2009; Jay, 2009; Woodworth, 2010] are based on tide gauge data located mainly along continental boundaries. Ray [2006, 2009] showed a largely coherent picture of a strongly decreasing $S_{2}$ amplitude and a moderately increasing $M_{2}$ amplitude 
along the eastern coast of North America. Since the $S_{2}$ tide is driven by the radiational forces of the sun, as well as by gravitational forces, Ray [2009] suggested that changes in the radiational forcing, i.e., in the pressure loading induced by the atmospheric tide, may account, in part, for the strong decrease in $S_{2}$ amplitude. Jay [2009] showed increasing $M_{2}$ and $K_{1}$ amplitudes for the western coast of North America. A regional study of the North Sea by Hollebrandse [2005] showed a nearly constant tidal range in the first half of the 20th century and a very strong increase in the tidal range of $\sim 2.5 \mathrm{~cm} \mathrm{decade}^{-1}$ in the second half.

[5] In most cases the physical processes responsible for these changes remain uncertain and any suggestions in this regard are somewhat speculative. As a further example, D. A. Greenberg et al. (Climate change, mean sea level and high tides in the Bay of Fundy, submitted to Atmosphere-Oceans, 2011) suggest that the trend in the $M_{2}$ amplitude in the Gulf of Maine is due to a change in water depth on the shelf in response to glacial isostatic adjustment (GIA).

[6] Understanding the changing oceanic response to tidal forces during the last century is not only an interesting academic issue but also a practical one. In some regions, where the trends in tidal amplitude are significant compared with changes in mean sea level, the evolving mean tidal range will have an impact on navigation, flooding risk assessment, protection of coastal zones, etc. Therefore, it is of considerable importance to understand the physical processes responsible for the observed trends. Further, if there is a connection between changes in climate and tides, long-term tide gauge records may contain more information than simply sea level.

[7] The present study comprises two different approaches: (1) an analysis of long-term sea level records in the Pacific and Atlantic and (2) sensitivity experiments performed with a one-layer global ocean tide model, in which the extent of the water column is altered according to plausible rates of present-day GIA and mean sea level rise.

[8] Long-term time series were not available for all regions of the global ocean. All of the data presented in this study are from tide gauges in the Pacific and Atlantic, mainly from the Northern Hemisphere. When analyzing the trend of phase and amplitude of a tidal constituent at a specific station, it is seldom possible to distinguish whether the trend has its origin in local or large-scale changes in sea level or stratification. In the case of the solar-influenced constituents, trends can even be caused by variations in radiational forcing. In regions where a sufficient number of stations with long-term sea level data are available, trends in tides seem to reflect a changing large-scale response of the ocean-to-tidal forces, rather than the appearance of local changes; these regions are described in section 3 . To increase confidence in the results, trends in both tidal amplitudes and phases are studied.

[9] We analyze data from 50 tide gauges. The method used to compute the tidal constituents $\left(M_{2}, S_{2}, K_{1}\right.$ and $\left.O_{1}\right)$ from the time series is, in principle, equivalent to the filter presented by Munk and Cartwright [1966]. In section 4, a local comparison between the tidal amplitude trend and the trend in mean sea level is considered. In this manner, we identify regions where it is important to include changes in mean tidal range in studies of the impact of rising sea level. In sections 5 and 6 we describe sensitivity experiments in which GIA associated with the last ice age and eustatic sea level rise are incorporated into a global barotropic tide model.
The changes induced by the GIA signal are analyzed in terms of free oscillations in section 7. In section 8, a coupled oscillator model of the tides is used to understand how small changes in coastal sea level can lead to changes in tides of the same order as those recorded in observations.

\section{Observational Basis and Tidal Trend Analysis}

[10] We analyzed hourly sea level time series from 50 observational stations obtained from the University of Hawaii Sea Level Center, British Oceanographic Data Centre, and Canadian Tides and Water Levels Data Archive. The stations are located along the Atlantic coast, the Pacific coast, and in the interior of the Pacific. The highest density of available long-term time series is along the North American Pacific and Atlantic coasts. In these regions, all time series are longer than 65 years, except for Queen Charlotte City, Canada (52 years) and Adak, USA (58 years). Along the European Atlantic coast, time series from five stations are available, with spans longer than 65 years. Three of those sites are directed to the open sea, one is located in the English Channel, and one is in the North Sea. Along the Northwest Pacific coast, a total of eight time series, including stations on the Japanese coast (record lengths of 42-48 years) and in the interior of the Pacific (record lengths of 50-95 years), are available. In the Southern Hemisphere we have only a few usable time series. Four of them are located along the South American Pacific coast, one on the South American Atlantic coast, and one in Australia. The length of these time series ranges from 40 to 62 years.

[11] At each station the time series are used from the year 1930 onward and are divided into yearly sections. The sections are included if gaps within a particular year do not exceed 10 days and the overall amount of missing data does not exceed 30 days. These gaps are filled using a standard tidal prediction method [Foreman, 1977]. The filter used to determine admittance is defined by an input function $G_{r}$ and a response function $H_{r}$ [Munk and Cartwright, 1966]

$$
\begin{aligned}
& G_{r}=\frac{2}{N} \sum_{t=1}^{355} \Psi(t) a(t) \exp (i 2 \pi r t / 355) \\
& H_{r}=\frac{2}{N} \sum_{t=1}^{355} \Psi(t) \zeta(t) \exp (i 2 \pi r t / 355),
\end{aligned}
$$

where $t$ represents the time in days $(-177$ to 177$)$ and $\Psi(t)=$ $1+\cos (\pi t / 355)$ is the cosine taper function. (This taper function weights the seasons of the year differently, e.g., summer is more strongly weighted than winter. We tested the sensitivity of the resulting trends using either the cosine or constant taper function $\Psi(t)=1$. Only the first decimal point of the centennial fractional trends are affected.) The function $\zeta(t)$ is the sea surface elevation time series of the tide gauge station, $a(t)$ is the real-time tidal potential, and $r$ is the frequency of the tidal constituent. The filter length of 355 days is chosen such that the frequencies $r$ are integer numbers for the 4 analyzed tidal constituents $M_{2}, S_{2}, K_{1}$ and $O_{1}$.

[12] The tidal potential is generated with the tidal module of Thomas et al. [2001], which computes the lunisolar 


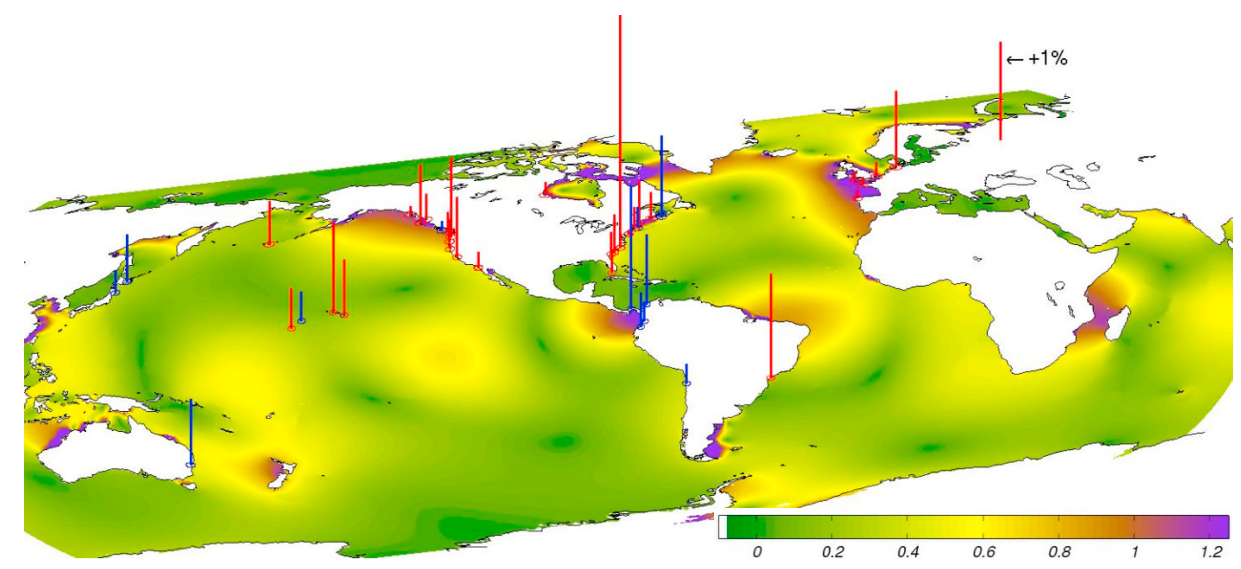

Figure 1. Fractional trends in $M_{2}$ amplitude. The reference bar on the Eurasian continent shows a trend of $1 \%$ decade $^{-1}$. Red (blue) bars denote positive (negative) trends. Color contours provide the tidal amplitude in m (TPXO.7.2) [Egbert et al., 1994].

tidal potential of second degree through a determination of real-time orbital positions of the sun and moon. This tidal potential of second degree associated with either the sun or moon can be written as a sum of the semidiurnal $\Phi_{s}$, diurnal $\Phi_{d}$ and long periodic $\Phi_{l}$ components

$$
\Phi_{2}(\phi, \lambda)=\Phi_{s}(\phi, \lambda)+\Phi_{d}(\phi, \lambda)+\Phi_{l}(\phi, \lambda) .
$$

[13] Each component of the potential is [e.g., Melchior, 1978]

$$
\begin{gathered}
\Phi_{s}(\phi, \lambda)=\frac{3}{4} \eta M \frac{R^{2}}{d_{E}^{3}} \cos ^{2}(\phi) \cos ^{2}(\delta) \cos (2 H(\phi, \lambda)), \\
\Phi_{d}(\phi, \lambda)=\frac{3}{4} \eta M \frac{R^{2}}{d_{E}^{3}} \sin (2 \phi) \sin (2 \delta) \cos (H(\phi, \lambda)), \\
\Phi_{l}(\phi, \lambda)=\frac{3}{4} \eta M \frac{R^{2}}{d_{E}^{3}} 3\left(\sin ^{2}(\phi)-\frac{1}{3}\right)\left(\sin ^{2}(\delta)-\frac{1}{3}\right),
\end{gathered}
$$

where $\phi$ and $\lambda$ are the geographical coordinates of latitude and longitude, respectively. $H(\phi, \lambda)=\Omega t_{\text {sid }}-\alpha-\lambda$ determines the relative longitude, taking into account the Earth's rotation $\Omega t_{\text {sid }}$, where $t_{\text {sid }}$ is the sidereal time, and $\alpha$ the right ascension. The Earth's radius is $R$, the distance from either sun or moon to the Earth is $d_{E}$, and $\eta$ is the gravitational constant. For the input function, the time-dependent orbital cycles are important, e.g., monthly, yearly, or 18.6 year cycles, but not the explicit dependence of the potential on geographical coordinates. Thus, the functions $a(t)$ in the input function can be written as

$$
\begin{gathered}
a_{s}(t)=\Phi_{s}\left(\phi_{s}, \lambda_{s}\right) \\
a_{d}(t)=\Phi_{d}\left(\phi_{d}, \lambda_{d}\right),
\end{gathered}
$$

where $a_{s}(t)$ and $a_{d}(t)$ are used to analyze the semidiurnal and diurnal constituents, respectively. The fixed geographical coordinates are defined as $\left(\phi_{s}, \lambda_{s}\right)=(0,0)$ and $\left(\phi_{d}, \lambda_{d}\right)=(45,0)$.
[14] Finally, the complex admittance is derived from (1) and (2)

$$
A_{r}=\frac{\left\langle G_{r} H_{r}^{*}\right\rangle}{\left\langle G_{r} G_{r}^{*}\right\rangle}
$$

and describes the response of the ocean at frequency $r$. The * denotes a complex conjugate and the brackets \langle\rangle describe an average over a certain time window. The time window is chosen to be 1 year, i.e., no averaging is performed, for the analysis of linear trends in time with amplitude $\left|A_{r s}\right|$ and $\operatorname{argument} \arg A_{r}$.

[15] The estimation of linear trends in the time series of amplitudes and phases is performed by means of generalized least squares (GLS). A linear model is applied for all stations and constituents except for the $M_{2}$ amplitudes inside the Gulf of Maine. There, the amplitude of the nodal cycle in the response of the ocean is reduced through nonlinear dynamics [Ku et al., 1985]. Since we explicitly include the amplitude of the nodal cycle in the input function (1), it is overestimated in the resulting admittance, and the time series of $M_{2}$ admittance shows an inverse 18.6 year cycle. These time series are corrected by the corresponding sinusoidal function

$$
\begin{aligned}
A_{M_{2}}\left(t^{\prime}\right)= & A_{0}+\delta A\left(t^{\prime}-1970\right) \\
& +A_{N} \sin \left(2 \pi / 18.5996\left(t^{\prime}-1973.66\right)\right),
\end{aligned}
$$

where $t^{\prime}$ is the time in years, $\delta A$ the linear trend and $A_{N}$ the amplitude of the nodal cycle to be corrected for.

[16] The regression model for estimating the linear trend is

$$
X(t)=\mu+\alpha t+\epsilon(t)
$$

with mean $\mu$ and linear trend $\alpha$. We assume that the errors $\epsilon(t)$ have zero mean, are stationary and autocorrelated in time. The autocorrelated errors are modeled by an autoregressive model (AR) (2) process, and following this the error-covariance matrix used for the GLS procedure is determined. We note that the trends and standard errors show little sensitivity to whether an autoregressive model $\mathrm{AR}(1)$ or $\mathrm{AR}(2)$ process is assumed. However, testing time series with 


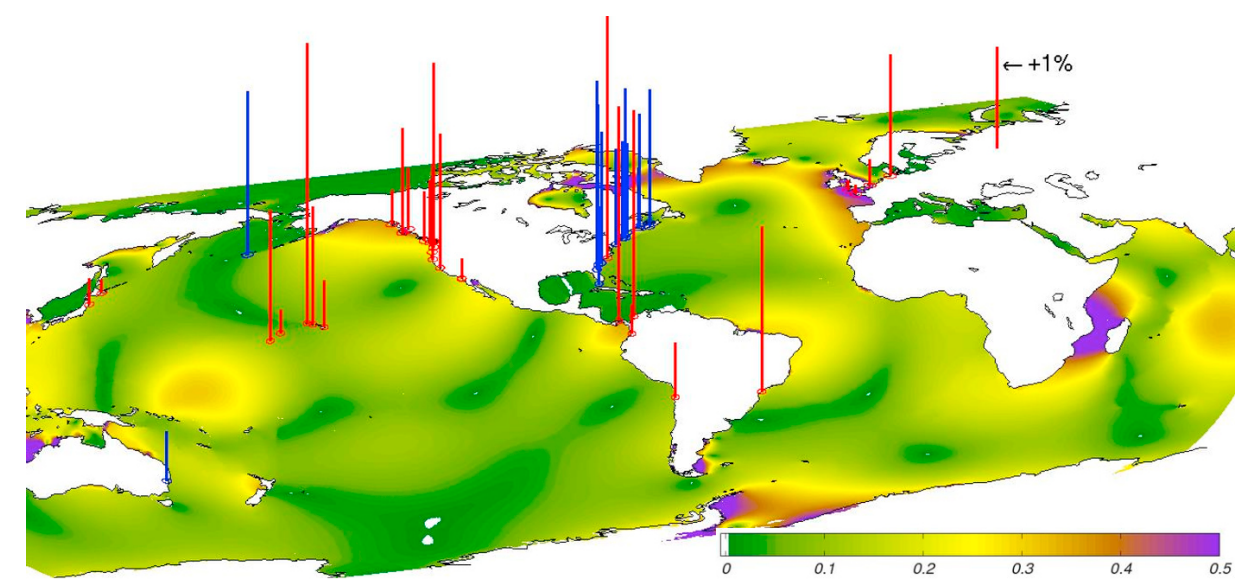

Figure 2. Fractional trends in $S_{2}$ amplitude. The reference bar on the Eurasian continent shows a trend of $1 \%$ decade $^{-1}$. Red (blue) bars denote positive (negative) trends. Color contours provide the tidal amplitude in m (TPXO.7.2) [Egbert et al., 1994].

the Auto Regressive Moving Average model suggests that the assumption of an $\operatorname{AR}(2)$ process is, in most cases, more appropriate.

\section{Secular Trends of Semidiurnal and Diurnal Tides}

[17] In the following, secular trends of $M_{2}, S_{2}, K_{1}$ and $O_{1}$ amplitudes and phases (where a positive phase trend corresponds to a decreasing phase lag) are discussed. Figures 1-4 show the fractional trends in tidal amplitudes at locations where trends are larger than their standard errors. In Figures 5 and 6, trends in amplitude are plotted against phase trends for particular regions. For these plots, the scaling of amplitude and phase are deduced from the following relation, which describes the change over the whole oscillation as

$$
a e^{i \phi} \rightarrow(a+\delta a) e^{i(\phi+\delta \phi)} \simeq a e^{i \phi}\left(1+\frac{\delta a}{a}\right)(1+i \delta \phi),
$$

where $\delta a$ and $\delta \phi$ are the changes of amplitude and phase, respectively. Thus, an appropriate scaling is to plot $\delta a / a$ versus $\delta \phi$. A complete listing of trends in amplitude and phase of each constituent and their respective standard errors is given in Tables 1 and 2 for all analyzed tide gauge stations.

\subsection{Pacific}

[18] In the Pacific almost all stations are in the Northern Hemisphere, except for one station in Australia (Fort Denison) and two stations along the coast of South America (Libertad, Ecuador; Antofagasta, Chile). Along the North American coast fourteen stations are analyzed, ranging from La Jolla, USA in the south to Adak, USA in the far north. A number of stations are analyzed in the Pacific deep ocean, as well as along the Japanese coast.

[19] At Fort Denison, Australia we see negative trends in tidal amplitude of $\sim-0.5 \%$ decade $^{-1}$ in all four analyzed constituents. Unfortunately, this is the only station in that region, and thus it is not clear whether the origin of these changes is of local or larger scale.

[20] Along the coast of North America, north of $30^{\circ} \mathrm{N}, M_{2}$ and $S_{2}$ trends in amplitude are consistently positive. The phase changes are positive for the $M_{2}$ constituent (except for Tofino, Canada), whereas the sign varies for $S_{2}$. Further, the

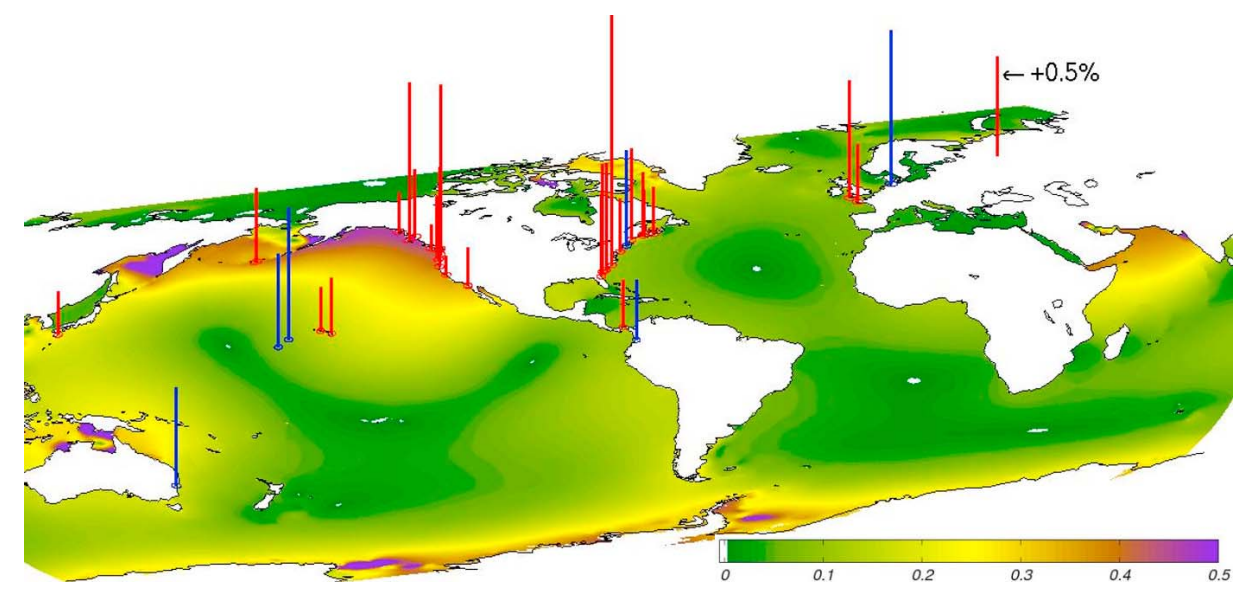

Figure 3. Fractional trends in $K_{1}$ amplitude. The reference bar on the Eurasian continent shows a trend of $0.5 \%$ decade $^{-1}$. Red (blue) bars denote positive (negative) trends. Color contours provide the tidal amplitude in m (TPXO.7.2) [Egbert et al., 1994]. 


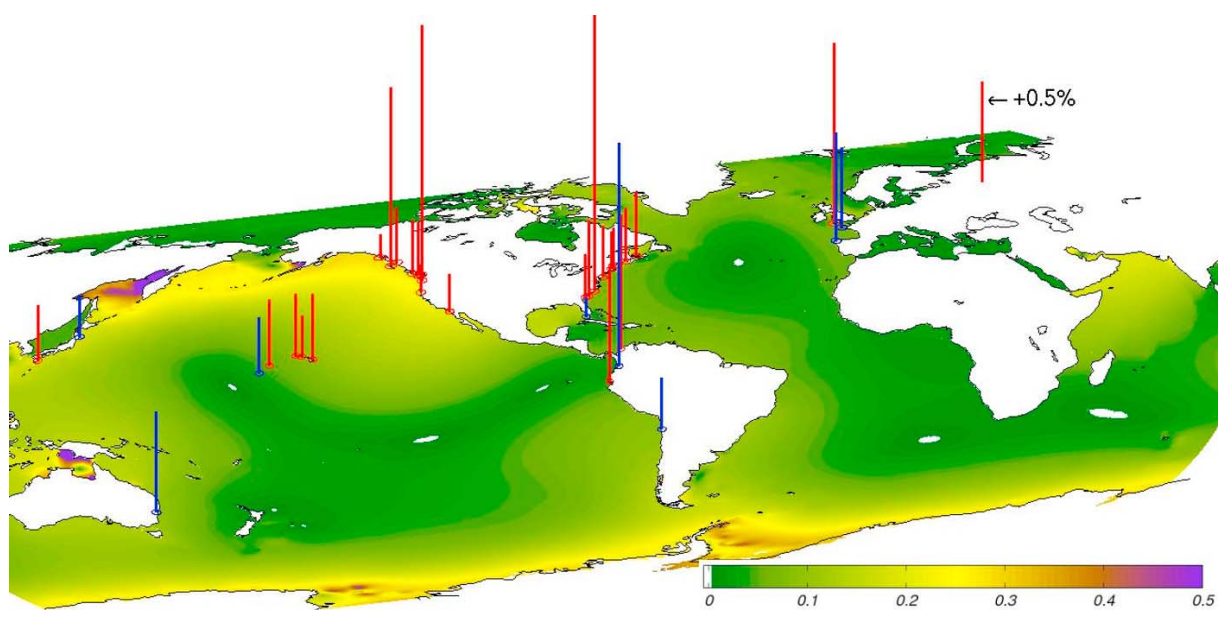

Figure 4. Fractional trends in $O_{1}$ amplitude. The reference bar on the Eurasian continent shows a trend of $0.5 \%$ decade $^{-1}$. Red (blue) bars denote positive (negative) trends. Color contours provide the tidal amplitude in m (TPXO.7.2) [Egbert et al., 1994].

phase and amplitude trends of the $M_{2}$ tide are positively correlated, i.e., larger changes in amplitude correspond to larger changes in phase, whereas for the $S_{2}$ tide no correlation is apparent (Figure 5). The largest amplitude changes along the coast of North America are at San Francisco, USA $\left(M_{2} \sim 0.6 \%\right.$ decade $^{-1}$ and $S_{2} \sim 1.3 \%$ decade $\left.^{-1}\right)$ and Astoria, USA $\left(M_{2} \sim 0.8 \%\right.$ decade $^{-1}$ and $S_{2} \sim 1.8 \%$ decade $\left.^{-1}\right)$. At most of the remaining stations the trends are moderate, with
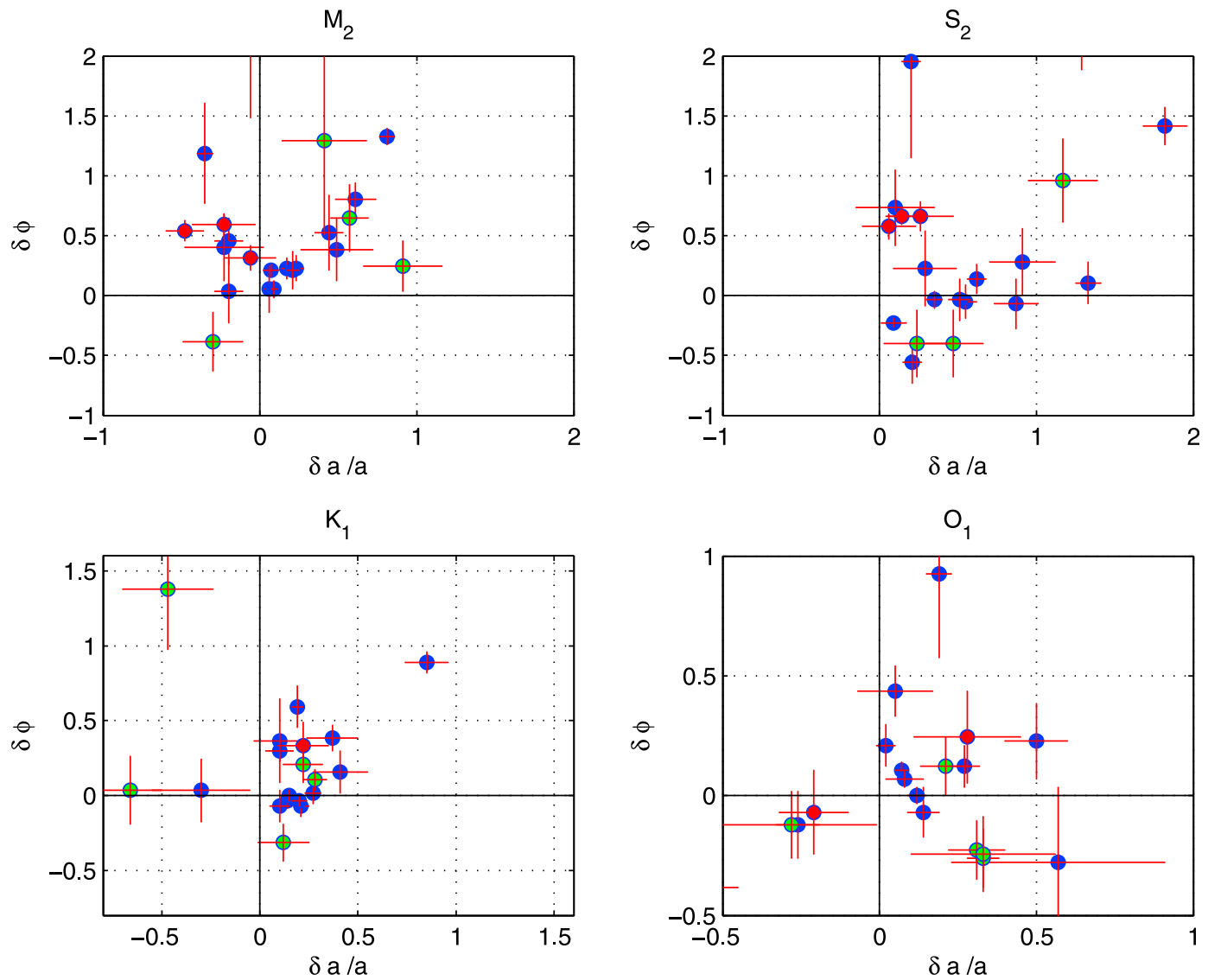

Figure 5. Trend of relative amplitude $\delta a / a$ in $\%$ decade $^{-1}$ versus phase $\delta \phi$ in $\left[\mathrm{rad}^{*} 100\right] \mathrm{decade}^{-1}$ for stations in the Pacific. See text for details on the scaling of amplitude and phase. Stations are plotted if the amplitude and/or phase trend is larger than its standard error, which is shown by the red crosses. Blue dots are stations along the American Pacific coast, green dots are stations in the middle of the Pacific, and red dots are sites along the Japanese coast. 

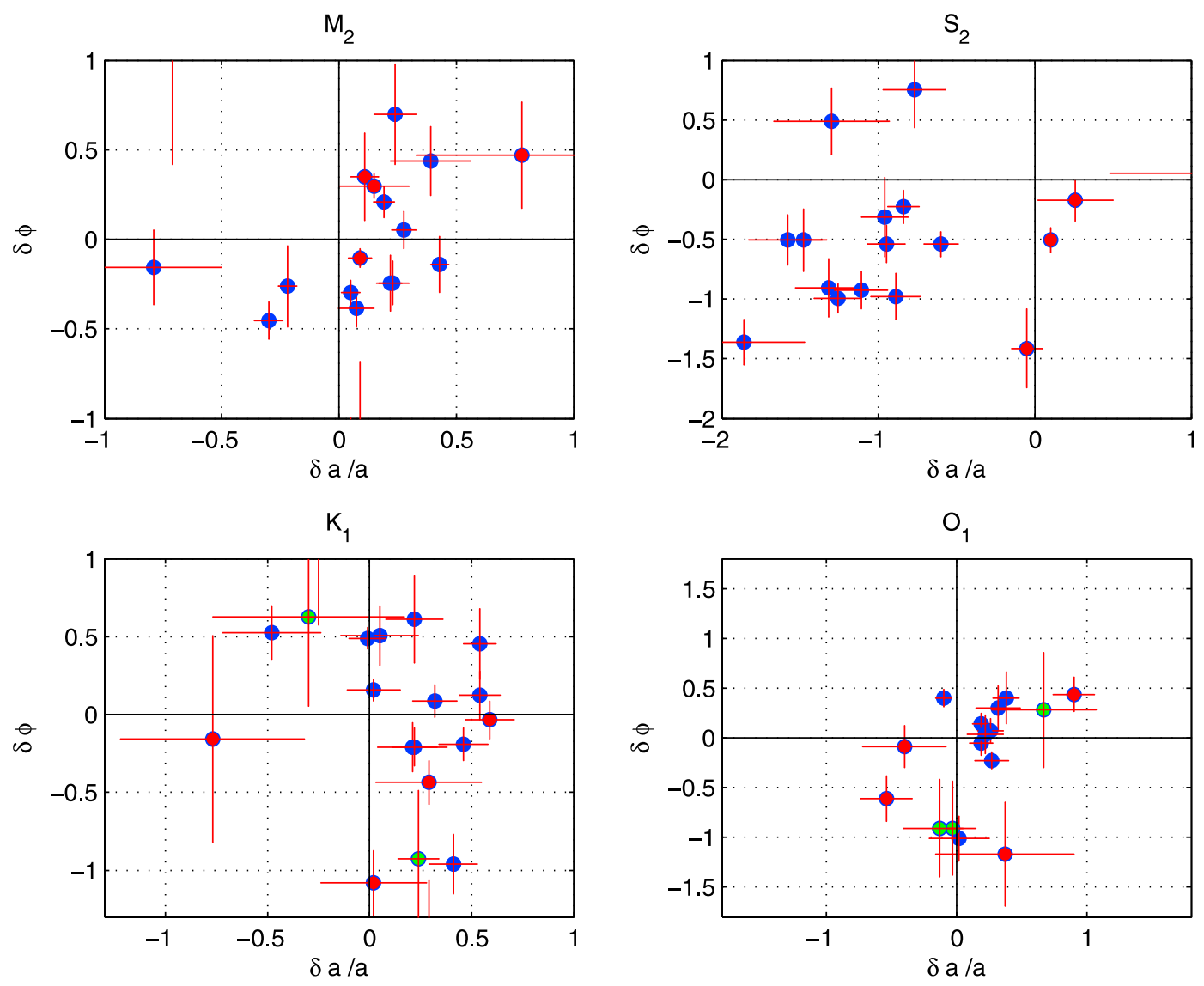

Figure 6. Trend of relative amplitude $\delta a / a$ in $\%$ decade $^{-1}$ versus phase $\delta \phi$ in $\left[\mathrm{rad}^{*} 100\right] \mathrm{decade}^{-1}$ for stations in the Atlantic. See text for details on the scaling of amplitude and phase. Stations are plotted if the amplitude and/or phase trend is larger than its standard error, which is shown by the red crosses. Blue dots are stations along the American coast, green dots are stations at the South American coast, and red dots are sites along the European coast.

values of $\sim 0.3 \%$ decade ${ }^{-1}$, while trends in $S_{2}$ amplitude tend to be larger than the corresponding ones in $M_{2}$. In the tropical Pacific region, along the American coast, $M_{2}$ has negative trends in amplitude $\left(\sim-0.2 \%\right.$ decade $\left.^{-1}\right)$ and $S_{2}$ has positive trends with values of $\sim 0.3 \%$ decade $^{-1}$.

[21] The diurnal constituents, $K_{1}$ and $O_{1}$, show positive amplitude trends along the North American Pacific coast with the exception of some stations south of $30^{\circ} \mathrm{N}$. Phase trends are positive for most of these stations. The Astoria station is once again characterized by large trends of phase and amplitude $\left(\sim 0.9 \%\right.$ for $K_{1}$ and $\sim 1.3 \%$ decade $^{-1}$ for $O_{1}$ amplitude) and a large trend in amplitude of $\sim 0.8 \%$ decade $^{-1}$ also occurs at Queen Charlotte City. All other stations show trends lower than $0.5 \%$ decade $^{-1}$ in amplitude and $0.6^{\circ}$ decade $^{-1}$ in phase.

[22] In the middle of the Pacific, most stations show positive tidal amplitude trends for $M_{2}$ and $S_{2}$, except for Wake Island which shows a negative trend in $M_{2}$. The positive trends have values in the range of 0.2 to $2.8 \%$ decade $^{-1}$, where again the largest trends occur for the $S_{2}$ constituent. The trends in the diurnal tidal amplitude of $K_{1}$ and $O_{1}$ are mixed. The amplitude trends of the $K_{1}$ tide are negative for the two western stations, Wake Island and Johnston Island, and are positive for Hilo and Honolulu. If the tidal amphidrome in the North Pacific is located between these two groups of islands, a slight eastward shift could explain this trend pattern and further the positive trends along the North American Pacific coast. However, results of tide models with assimilation of satellite data simulate an amphidromic location west of these island at approximately $180^{\circ} \mathrm{E}$ and thus the explanation for this pattern is not obvious.

[23] We performed a response analysis of the entire semidiurnal and diurnal band at Honolulu, USA (Figure 7), which has the longest sea level record in the Pacific deep ocean. Our analysis compares records over a 12 year time period at both the start (1916) and end (2008) of the time series. The tidal response of the deep Pacific Ocean, measured at the Honolulu station, changed slightly over the last century in the magnitude of the admittance over the entire semidiurnal and diurnal frequency band and an almost uniform and large negative change in phase lag. Colosi and Munk [2006] attributed the change in $M_{2}$ amplitude and phase to changes in the internal tide field and it may be that this impact extends to other diurnal and semidiurnal constituents.

[24] Along the Japanese coast, the trend in $M_{2}$ is positive and associated with a negative trend in phase. In contrast, $S_{2}$ has no significant change in amplitude, but the phase of this 
Table 1. Results of the Trend Analyses of the Semidiurnal Constituents $M_{2}$ and $S_{2}{ }^{\text {a }}$

\begin{tabular}{|c|c|c|c|c|c|c|}
\hline \multirow[b]{2}{*}{ Station } & \multicolumn{3}{|c|}{$M_{2}$} & \multicolumn{3}{|c|}{$S_{2}$} \\
\hline & $a$ & $\frac{\delta a}{a} 10$ & $\delta \phi 10$ & $a$ & $\frac{\delta a}{a} 10$ & $\delta \phi 10$ \\
\hline Churchill, Canada & 155 & $1.4 \pm 1.2$ & $-1.6 \pm 0.9$ & 47 & $2.3 \pm 3.2$ & $-7.5 \pm 1.5$ \\
\hline Charlottetown, Canada & 76 & $-7.9 \pm 2.9$ & $-0.9 \pm 1.2$ & 18 & $-13.2 \pm 2.1$ & $-5.2 \pm 1.4$ \\
\hline Halifax, Canada & 63 & $-3.0 \pm 0.6$ & $-2.6 \pm 0.6$ & 14 & $-12.6 \pm 1.5$ & $-5.7 \pm 0.7$ \\
\hline St. John, Canada & 303 & $0.9 \pm 0.8$ & $-2.2 \pm 0.6$ & 49 & $-10.8 \pm 0.9$ & $-5.3 \pm 0.9$ \\
\hline Eastport, USA & 264 & $2.8 \pm 0.4$ & $0.3 \pm 0.6$ & 42 & $-6.1 \pm 0.6$ & $-3.1 \pm 0.6$ \\
\hline Portland, USA & 136 & $4.4 \pm 0.5$ & $-0.8 \pm 0.9$ & 21 & $-8.8 \pm 1.4$ & $-5.6 \pm 1.1$ \\
\hline Boston, USA & 137 & $1.9 \pm 0.4$ & $1.2 \pm 0.5$ & 22 & $-8.4 \pm 0.7$ & $-1.3 \pm 0.8$ \\
\hline Newport, USA & 51 & $-2.2 \pm 0.4$ & $-1.5 \pm 1.3$ & 11 & $-14.8 \pm 1.2$ & $-2.9 \pm 1.5$ \\
\hline New London, USA & 36 & $2.2 \pm 0.5$ & $-1.4 \pm 0.9$ & 7 & $-9.6 \pm 1.5$ & $-1.8 \pm 1.9$ \\
\hline Atlantic City, USA & 59 & $0.5 \pm 0.4$ & $-1.7 \pm 0.4$ & 12 & $-9.5 \pm 1.2$ & $-3.1 \pm 0.9$ \\
\hline Wilmington, USA & 56 & $51.3 \pm 5.5$ & $28.7 \pm 1.9$ & 7 & $58.3 \pm 7.2$ & $20.3 \pm 1.7$ \\
\hline Charleston, USA & 77 & $3.9 \pm 1.7$ & $2.5 \pm 1.1$ & 13 & $-13.0 \pm 3.7$ & $2.8 \pm 1.6$ \\
\hline Fort Pulaski, USA & 101 & $2.3 \pm 0.7$ & $-1.4 \pm 0.7$ & 17 & $-15.8 \pm 2.5$ & $-2.9 \pm 1.2$ \\
\hline Mayport, USA & 66 & $0.5 \pm 1.7$ & $-6.6 \pm 0.9$ & 11 & $-18.6 \pm 3.9$ & $-7.8 \pm 1.1$ \\
\hline Key West, USA & 17 & $2.4 \pm 0.9$ & $4.0 \pm 1.6$ & 5 & $-7.7 \pm 2.0$ & $4.3 \pm 1.8$ \\
\hline Christobal, Panama & 77 & $-12.4 \pm 3.6$ & $-10.2 \pm 4.2$ & 13 & $21.2 \pm 2.6$ & $-16.7 \pm 7.0$ \\
\hline Cartagena, Colombia & 7 & $-7.1 \pm 5.9$ & $7.1 \pm 4.7$ & 2 & $20.4 \pm 7.4$ & $7.7 \pm 7.9$ \\
\hline Cananeia, Brazil & 36 & $10.6 \pm 1.2$ & $-12.7 \pm 5.2$ & 23 & $16.3 \pm 2.4$ & $-20.5 \pm 6.2$ \\
\hline La Coruna, Spain & 118 & $0.9 \pm 0.5$ & $-5.8 \pm 1.9$ & 41 & $-0.5 \pm 1.0$ & $-8.1 \pm 1.9$ \\
\hline Brest, France & 205 & $0.9 \pm 0.5$ & $-0.6 \pm 0.3$ & 75 & $1.0 \pm 0.4$ & $-2.9 \pm 0.6$ \\
\hline Newelyn, UK & 171 & $1.1 \pm 0.6$ & $2.0 \pm 1.4$ & 57 & $1.1 \pm 1.1$ & $-0.2 \pm 1.5$ \\
\hline Dover, UK & 226 & $1.5 \pm 1.5$ & $1.7 \pm 0.4$ & 71 & $2.6 \pm 2.4$ & $-1.0 \pm 1.0$ \\
\hline Cuxhaven, Germany & 136 & $7.8 \pm 4.5$ & $2.7 \pm 1.7$ & 35 & $12.0 \pm 7.2$ & $0.3 \pm 2.7$ \\
\hline Antofagasta, Chile & 37 & $-2.0 \pm 0.9$ & $2.6 \pm 1.1$ & 11 & $5.5 \pm 0.7$ & $-0.3 \pm 0.8$ \\
\hline Libertad, Ecuador & 78 & $-2.3 \pm 2.5$ & $2.3 \pm 1.6$ & 22 & $1.2 \pm 2.4$ & $1.7 \pm 2.0$ \\
\hline Tumaco, Colombia & 120 & $-3.5 \pm 0.5$ & $6.8 \pm 2.4$ & 32 & $1.0 \pm 2.5$ & $4.2 \pm 1.8$ \\
\hline Buenaventura, Colombia & 150 & $-2.0 \pm 0.9$ & $0.2 \pm 1.5$ & 40 & $2.9 \pm 2.0$ & $1.3 \pm 1.8$ \\
\hline La Jolla, USA & 50 & $1.7 \pm 0.3$ & $1.3 \pm 0.5$ & 20 & $2.1 \pm 0.6$ & $-3.2 \pm 1.0$ \\
\hline Los Angeles, USA & 51 & $0.7 \pm 0.5$ & $1.2 \pm 0.3$ & 20 & $0.9 \pm 0.8$ & $-1.3 \pm 0.2$ \\
\hline San Diego, USA & 54 & $-0.6 \pm 0.9$ & $12.1 \pm 3.6$ & 22 & $2.0 \pm 0.6$ & $11.2 \pm 4.6$ \\
\hline San Francisco, USA & 57 & $6.1 \pm 1.3$ & $4.6 \pm 0.8$ & 13 & $13.3 \pm 0.8$ & $0.6 \pm 1.0$ \\
\hline Crescent City, USA & 71 & $0.6 \pm 0.3$ & $0.3 \pm 1.1$ & 18 & $5.1 \pm 0.7$ & $-0.2 \pm 1.0$ \\
\hline South Beach, USA & 88 & $2.3 \pm 0.5$ & $1.3 \pm 0.6$ & 23 & $8.7 \pm 1.4$ & $-0.4 \pm 1.2$ \\
\hline Astoria, USA & 94 & $8.1 \pm 0.5$ & $7.6 \pm 0.4$ & 23 & $18.2 \pm 1.4$ & $8.1 \pm 0.9$ \\
\hline Neah Bay, USA & 78 & $2.1 \pm 0.4$ & $1.2 \pm 0.9$ & 23 & $6.2 \pm 0.6$ & $0.8 \pm 0.7$ \\
\hline Victoria, Canada & 37 & $4.9 \pm 2.3$ & $2.2 \pm 1.5$ & 10 & $9.1 \pm 2.1$ & $1.6 \pm 1.6$ \\
\hline Tofino, Canada & 98 & $-1.0 \pm 0.5$ & $-1.3 \pm 0.8$ & 28 & $4.9 \pm 0.7$ & $-1.8 \pm 1.0$ \\
\hline Queen Charlotte City, Canada & 196 & $5.9 \pm 0.8$ & $0.2 \pm 0.7$ & 64 & $10.4 \pm 0.5$ & $-0.1 \pm 0.8$ \\
\hline Prince Rupert, Canada & 194 & $2.7 \pm 1.3$ & $-0.1 \pm 0.4$ & 63 & $6.1 \pm 0.8$ & $-0.7 \pm 0.7$ \\
\hline Sitka, USA & 110 & $0.9 \pm 0.2$ & $0.3 \pm 0.4$ & 35 & $3.5 \pm 0.5$ & $-0.2 \pm 0.4$ \\
\hline Adak, USA & 19 & $4.4 \pm 0.9$ & $3.0 \pm 1.8$ & 2 & $-16.2 \pm 7.0$ & $28.1 \pm 2.7$ \\
\hline Hilo, USA & 22 & $5.7 \pm 1.2$ & $3.7 \pm 1.6$ & 9 & $4.7 \pm 1.9$ & $-2.3 \pm 1.6$ \\
\hline Honolulu, USA & 17 & $9.1 \pm 2.5$ & $1.4 \pm 1.2$ & 5 & $11.7 \pm 2.2$ & $5.5 \pm 2.0$ \\
\hline Nawiliwili, USA & 15 & $3.3 \pm 5.0$ & $-1.0 \pm 1.5$ & 5 & $27.7 \pm 4.0$ & $-1.1 \pm 2.1$ \\
\hline Wake Island, USA & 28 & $-3.0 \pm 1.9$ & $-2.2 \pm 1.4$ & 14 & $2.4 \pm 2.1$ & $-2.3 \pm 1.6$ \\
\hline Johnston Island, USA & 26 & $4.1 \pm 2.7$ & $7.4 \pm 4.5$ & 10 & $12.9 \pm 3.4$ & $13.8 \pm 3.0$ \\
\hline Kushiro, Japan & 29 & $-4.8 \pm 1.2$ & $3.1 \pm 0.5$ & 13 & $1.4 \pm 1.0$ & $3.8 \pm 0.4$ \\
\hline Ofunato, Japan & 31 & $-2.3 \pm 2.0$ & $3.4 \pm 0.5$ & 14 & $2.6 \pm 2.1$ & $3.8 \pm 0.7$ \\
\hline Aburatsu, Japan & 53 & $-0.6 \pm 1.6$ & $1.8 \pm 0.6$ & 23 & $0.6 \pm 1.7$ & $3.3 \pm 0.6$ \\
\hline Fort Denison, Australia & 51 & $-6.7 \pm 2.0$ & $0.5 \pm 2.4$ & 13 & $-4.9 \pm 3.0$ & $3.1 \pm 2.2$ \\
\hline
\end{tabular}

${ }^{a}$ The amplitudes $a$ are given in cm, the relative amplitude trends $\frac{\delta a}{a}$ are given in $\%$ decade ${ }^{-1}$, and the phase trends in ${ }^{\circ}$ decade $^{-1}$. Amplitudes $a$ are The amplitudes $a$ are given in $\mathrm{cm}$, the
computed with respect to the year 1970 .

constituent is characterized by an almost uniform trend of $\sim 0.4^{\circ}$ decade $^{-1}$ in this region (Figure 5).

\subsection{Atlantic}

[25] In the North Atlantic, along the North American coast and the Gulf of Mexico, long-term sea level data exists for a well distributed network of tide gauge stations. The trends in $M_{2}$ amplitude are positive at most locations, with values of 0.2 to $0.4 \%$ decade $^{-1}$. The only locations with negative changes are north of the Gulf of Maine (Halifax, Canada; Charlottetown, Canada), as well as Newport, USA, close to the southern mouth of the Gulf of Maine. By far the largest trend occurs at Wilmington, USA $\left(5.1 \%\right.$ decade $\left.^{-1}\right)$ connected with a very large phase trend $\left(2.9^{\circ}\right.$ decade $\left.^{-1}\right)$.

[26] The $S_{2}$ amplitude trends at all stations (except Wilmington) along the North American Atlantic coast are negative with high values of up to $1.8 \%$ decade $^{-1}$. The large negative $S_{2}$ trends along the North American Atlantic coast are associated with consistently negative phase trends of $\sim-0.3^{\circ}$ decade $^{-1}$ (Figure 6). Only the Charleston, Wilmington, and Key West trends in phase are positive. These results for the $M_{2}$ and $S_{2}$ tides are consistent with the results of Ray [2009]. 
Table 2. As in Table 1, but for the Diurnal Constituents $O_{1}$ and $K_{1}$

\begin{tabular}{|c|c|c|c|c|c|c|}
\hline \multirow[b]{2}{*}{ Station } & \multicolumn{3}{|c|}{$O_{1}$} & \multicolumn{3}{|c|}{$K_{1}$} \\
\hline & $a$ & $\frac{\delta a}{a} 10$ & $\delta \phi 10$ & $a$ & $\frac{\delta a}{a} 10$ & $\delta \phi 10$ \\
\hline Churchill, Canada & 4 & $4.2 \pm 6.9$ & $5.6 \pm 7.6$ & 9 & $-1.9 \pm 3.9$ & $-2.3 \pm 3.5$ \\
\hline Charlottetown, Canada & 23 & $3.2 \pm 1.7$ & $1.7 \pm 1.3$ & 25 & $2.2 \pm 1.4$ & $3.5 \pm 1.6$ \\
\hline Halifax, Canada & 5 & $-3.2 \pm 3.6$ & $0.9 \pm 2.2$ & 10 & $2.1 \pm 1.7$ & $-1.2 \pm 0.9$ \\
\hline St. John, Canada & 12 & $-1.7 \pm 1.9$ & $-1.6 \pm 2.6$ & 16 & $2.2 \pm 1.1$ & $-1.2 \pm 0.7$ \\
\hline Eastport, USA & 12 & $2.7 \pm 1.3$ & $-1.3 \pm 0.5$ & 15 & $3.2 \pm 1.1$ & $0.5 \pm 0.6$ \\
\hline Portland, USA & 11 & $1.9 \pm 0.9$ & $-0.3 \pm 0.7$ & 14 & $4.6 \pm 1.2$ & $-1.1 \pm 0.6$ \\
\hline Boston, USA & 12 & $1.9 \pm 0.7$ & $0.8 \pm 0.6$ & 14 & $0.2 \pm 1.3$ & $0.9 \pm 0.4$ \\
\hline Newport, USA & 5 & $-3.5 \pm 3.8$ & $-0.7 \pm 1.5$ & 6 & $0.5 \pm 1.9$ & $2.9 \pm 1.1$ \\
\hline New London, USA & 5 & $0.2 \pm 2.9$ & $1.5 \pm 1.6$ & 8 & $-4.8 \pm 2.4$ & $3.0 \pm 1.0$ \\
\hline Atlantic City, USA & 8 & $2.6 \pm 1.0$ & $0.4 \pm 0.7$ & 11 & $2.7 \pm 1.5$ & $-2.2 \pm 0.5$ \\
\hline Wilmington, USA & 6 & $29.3 \pm 2.9$ & $17.4 \pm 2.5$ & 8 & $38.1 \pm 4.4$ & $20.2 \pm 1.5$ \\
\hline Charleston, USA & 8 & $3.8 \pm 1.0$ & $2.3 \pm 1.5$ & 11 & $5.4 \pm 0.8$ & $2.6 \pm 1.3$ \\
\hline Fort Pulaski, USA & 8 & $2.2 \pm 1.4$ & $0.2 \pm 1.1$ & 11 & $5.4 \pm 1.0$ & $0.7 \pm 0.9$ \\
\hline Mayport, USA & 6 & $0.2 \pm 2.3$ & $-5.8 \pm 1.3$ & 8 & $4.1 \pm 1.2$ & $-5.5 \pm 1.1$ \\
\hline Key West, USA & 9 & $-1.0 \pm 0.6$ & $2.3 \pm 0.5$ & 9 & $-0.1 \pm 0.9$ & $2.8 \pm 0.4$ \\
\hline Christobal, Panama & 8 & $-0.3 \pm 0.8$ & $-5.2 \pm 2.7$ & 11 & $2.4 \pm 1.0$ & $-5.3 \pm 2.5$ \\
\hline Cartagena, Colombia & 6 & $6.7 \pm 4.0$ & $1.6 \pm 3.3$ & 10 & $-3.0 \pm 4.7$ & $3.6 \pm 3.3$ \\
\hline Cananeia, Brazil & 11 & $-1.3 \pm 2.8$ & $-5.2 \pm 2.8$ & 7 & $2.9 \pm 3.7$ & $-8.6 \pm 2.5$ \\
\hline La Coruna, Spain & 7 & $-5.4 \pm 2.0$ & $-3.5 \pm 1.3$ & 7 & $0.2 \pm 2.6$ & $-6.2 \pm 1.2$ \\
\hline Brest, France & 7 & $-4.0 \pm 3.2$ & $-0.5 \pm 1.2$ & 6 & $2.9 \pm 2.6$ & $-2.5 \pm 0.8$ \\
\hline Newelyn, UK & 5 & $9.0 \pm 1.6$ & $2.5 \pm 1.0$ & 6 & $5.9 \pm 1.2$ & $-0.2 \pm 0.7$ \\
\hline Dover, UK & 6 & $3.7 \pm 5.3$ & $-6.7 \pm 3.0$ & 5 & $-2.5 \pm 8.7$ & $6.9 \pm 3.6$ \\
\hline Cuxhaven, Germany & 9 & $-0.6 \pm 4.5$ & $1.3 \pm 4.0$ & 7 & $-7.7 \pm 4.5$ & $-0.9 \pm 3.8$ \\
\hline Antofagasta, Chile & 9 & $-2.6 \pm 0.7$ & $-0.7 \pm 0.8$ & 15 & $0.1 \pm 0.7$ & $0.2 \pm 0.5$ \\
\hline Libertad, Ecuador & 3 & $5.7 \pm 3.4$ & $-1.6 \pm 1.8$ & 11 & $-0.3 \pm 2.6$ & $0.5 \pm 1.4$ \\
\hline Tumaco, Colombia & 2 & $-3.2 \pm 7.1$ & $-2.0 \pm 2.3$ & 11 & $1.0 \pm 1.3$ & $2.1 \pm 1.6$ \\
\hline Buenaventura, Colombia & 3 & $-11.1 \pm 6.6$ & $-2.2 \pm 10.6$ & 12 & $-3.0 \pm 2.5$ & $0.2 \pm 1.2$ \\
\hline La Jolla, USA & 21 & $0.7 \pm 0.2$ & $0.6 \pm 0.2$ & 33 & $1.4 \pm 0.3$ & $-0.2 \pm 0.3$ \\
\hline Los Angeles, USA & 22 & $0.8 \pm 0.6$ & $0.4 \pm 0.2$ & 34 & $1.5 \pm 0.4$ & $0.0 \pm 0.2$ \\
\hline San Diego, USA & 22 & $1.9 \pm 0.4$ & $5.3 \pm 2.0$ & 34 & $1.9 \pm 0.3$ & $3.4 \pm 0.8$ \\
\hline San Francisco, USA & 23 & $0.2 \pm 0.3$ & $1.2 \pm 0.5$ & 37 & $1.0 \pm 0.7$ & $1.7 \pm 0.4$ \\
\hline Crescent City, USA & 24 & $1.4 \pm 0.5$ & $-0.4 \pm 0.6$ & 39 & $1.0 \pm 0.5$ & $-0.4 \pm 0.6$ \\
\hline South Beach, USA & 27 & $0.4 \pm 0.7$ & $0.2 \pm 0.5$ & 43 & $2.1 \pm 0.4$ & $-0.4 \pm 0.4$ \\
\hline Astoria, USA & 24 & $12.7 \pm 1.6$ & $7.0 \pm 0.8$ & 39 & $8.5 \pm 1.1$ & $5.1 \pm 0.4$ \\
\hline Neah Bay, USA & 31 & $2.7 \pm 0.5$ & $0.7 \pm 0.5$ & 49 & $2.7 \pm 0.4$ & $0.1 \pm 0.4$ \\
\hline Victoria, Canada & 38 & $5.0 \pm 1.0$ & $1.3 \pm 0.9$ & 63 & $4.1 \pm 1.4$ & $0.9 \pm 0.8$ \\
\hline Tofino, Canada & 24 & $2.7 \pm 1.9$ & $-2.4 \pm 0.9$ & 39 & $1.2 \pm 0.8$ & $-0.8 \pm 0.5$ \\
\hline Queen Charlotte City, Canada & 30 & $8.9 \pm 1.4$ & $-0.7 \pm 0.4$ & 51 & $7.9 \pm 0.5$ & $-0.2 \pm 0.4$ \\
\hline Prince Rupert, Canada & 31 & $2.8 \pm 2.0$ & $-1.2 \pm 0.7$ & 51 & $3.4 \pm 1.1$ & $0.0 \pm 0.2$ \\
\hline Sitka, USA & 28 & $1.2 \pm 0.3$ & $-0.0 \pm 0.2$ & 46 & $2.0 \pm 0.4$ & $-0.2 \pm 0.2$ \\
\hline Adak, USA & 29 & $0.5 \pm 1.2$ & $2.5 \pm 0.6$ & 41 & $3.7 \pm 1.3$ & $2.2 \pm 0.5$ \\
\hline Hilo, USA & 9 & $3.3 \pm 0.5$ & $-1.5 \pm 0.7$ & 16 & $2.8 \pm 0.6$ & $0.6 \pm 0.4$ \\
\hline Honolulu, USA & 8 & $2.1 \pm 0.8$ & $0.7 \pm 0.7$ & 15 & $2.2 \pm 1.0$ & $1.2 \pm 0.7$ \\
\hline Nawiliwili, USA & 8 & $3.1 \pm 0.9$ & $-1.3 \pm 0.7$ & 15 & $1.2 \pm 1.3$ & $-1.8 \pm 0.7$ \\
\hline Wake Island, USA & 5 & $3.3 \pm 2.3$ & $-1.4 \pm 0.9$ & 6 & $-6.6 \pm 1.6$ & $0.2 \pm 1.3$ \\
\hline Johnston Island, USA & 3 & $-2.8 \pm 2.7$ & $-0.7 \pm 0.8$ & 8 & $-4.7 \pm 2.3$ & $7.9 \pm 2.3$ \\
\hline Kushiro, Japan & 20 & $-2.7 \pm 4.2$ & $0.4 \pm 2.6$ & 25 & $-1.1 \pm 2.6$ & $0.5 \pm 1.2$ \\
\hline Ofunato, Japan & 19 & $-2.1 \pm 1.1$ & $-0.4 \pm 1.0$ & 23 & $-1.0 \pm 1.1$ & $0.5 \pm 1.0$ \\
\hline Aburatsu, Japan & 18 & $2.8 \pm 1.7$ & $1.4 \pm 1.1$ & 23 & $2.2 \pm 1.3$ & $1.9 \pm 0.9$ \\
\hline Fort Denison, Australia & 10 & $-5.0 \pm 2.2$ & $1.5 \pm 1.2$ & 15 & $-4.9 \pm 2.0$ & $-0.3 \pm 1.6$ \\
\hline
\end{tabular}

[27] Diurnal tides along the North American Atlantic coast show remarkably uniform and positive trends, in both analyzed diurnal constituents, of $\sim 0.4 \%$ decade $^{-1}$ for $K_{1}$ and $0.2 \%$ decade $^{-1}$ for $O_{1}$. In the case of $K_{1}$, this is accompanied by small negative phase trends at most stations. Again, Wilmington, USA is characterized by an exceptionally large positive amplitude trend, similar to the results for the semidiurnal tidal trends. For both semidiurnal and diurnal tides, Wilmington shows much larger trends than all other stations along the North American coast. These anomalous trends suggest that local factors are playing a dominant role at Wilmington. Both Flick et al. [2003] and Ray [2009] also point to this unique behavior of the Wilmington tides, though an explanation for the strong increase has not yet been found.

[28] The three stations on the European coast that are located toward the North Atlantic show small positive trends $\left(\sim 0.1 \%\right.$ decade $\left.^{-1}\right)$ in $M_{2}$ and $S_{2}$ amplitude. Although the relative trend is $\sim 0.1 \%$ change per decade, the absolute trend is $0.1-0.2 \mathrm{~cm} \mathrm{decade}^{-1}$ due to the strong semidiurnal tide in that region. Semidiurnal phase trends do not show a consistent picture in this region and the changes in diurnal amplitude and phase are also highly variable.

[29] Two other stations on the European coast were analyzed, one in the English Channel (Dover, UK) and one in the North Sea (Cuxhaven, Germany). At Dover, the $M_{2}$ and $S_{2}$ 
(a) Honolulu semidiurnal

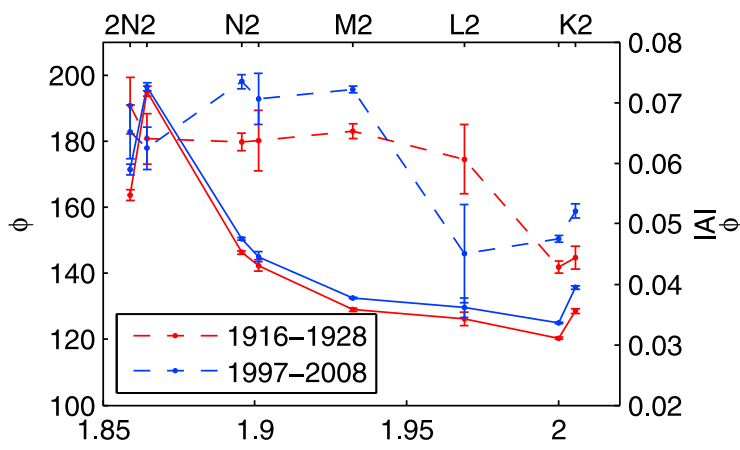

(b) Honolulu diurnal

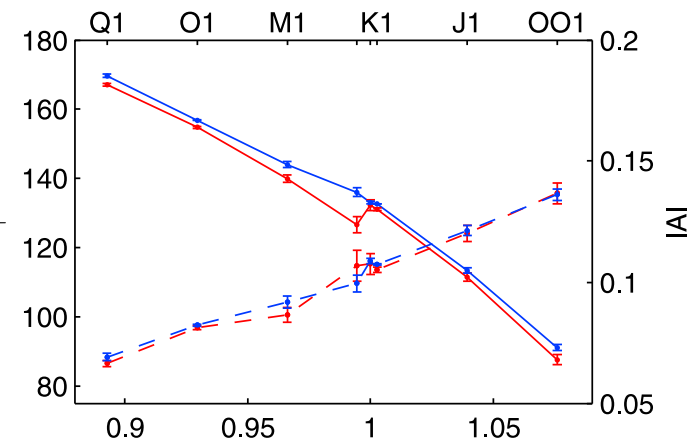

Figure 7. Admittance $|A|$ and phase $\phi$ in the (a) semidiurnal and (b) diurnal band for Honolulu, USA. The $y$ axis is given in counts per day. Dashed line is the admittance and solid line is the phase. Red (blue) lines are from the epoch of the 12 first (last) years of the sea level record.

trends are not significant and at Cuxhaven these trends are positive. The results for Cuxhaven are consistent with the analysis of Hollebrandse [2005], who analyzed a set of sea level records along the German and Dutch coasts and showed a strong trend in the tidal range after the year 1955 .

[30] In the South Atlantic only four stations are available, one on the coast of South America and three on the African coast, in South Africa. The station on the South American coast at Cananeia, Brazil shows large trends in $M_{2}$ and $S_{2}$ amplitude of 1.1 and $1.6 \%$ decade $^{-1}$, respectively. The three stations on the South African coast, Port Nolloth, Simons Town and Cape Town, have relatively short time series, starting at about 1960. Unfortunately, the quality of the data over the last 15 years is poor and there are many gaps in the records. Additionally, the robustness of the analysis at those sites is questionable, since the amplitude and phase evolution of the tide series show a bump in the year 1997, most likely due to the exchange of the float tide gauges by acoustic tide gauges at this time. Accordingly, we decided not to incorporate these sea level records in the present paper, although data in this region would allow a useful follow-up study to the analysis of Cartwright [1971]. Specifically, he analyzed data sets for the years 1761 and 1969 and inferred a phase change in the diurnal tides at St. Helena, UK within the South Atlantic deep ocean.

\section{Trends of Tides Versus Mean Sea Level}

[31] In this section, the trends in tidal amplitude at each station are compared with the associated trends in mean local sea level. The term "mean sea level trend", refers to the relative sea level trend measured at the tide gauge without corrections for GIA. In Figure 8, a subset of stations is shown, where the sum of $M_{2}, S_{2}, K_{1}$ and $O_{1}$ absolute tidal amplitude trends exceeds $10 \%$ of the trend in mean sea level. This subset includes 34 out of 50 analyzed stations, whereas some of them show trends of opposite sign to the mean sea level trends. An example is Fort Denison, where tidal trends are negative and the mean sea level trend is positive. In this case, the reduction in tidal amplitudes will counter the mean sea level rise in climate impact studies. In contrast, at Astoria and Crescent City, the tidal trend is positive and the sea level trend is negative, and thus the former may dominate such studies.

[32] Astoria and Wilmington show the largest differences between trends in mean sea level and tides. However, there are several other regions where less dramatic but still significant contributions to sea level changes exist. In the Gulf of Maine region the present mean sea level trend is $\sim 2.0 \mathrm{~cm}$ decade $^{-1}$, whereas the $M_{2}$ tidal amplitude, for example at Eastport, USA, changes at a rate of almost $0.7 \mathrm{~cm}$ decade ${ }^{-1}$. A similar situation occurs on the North American Pacific coast where the $M_{2}$ and $S_{2}$ tidal constituents at San Francisco significantly contribute to a rise of the mean tidal range. There, the trend in mean sea level is $2.1 \mathrm{~cm}$ decade $^{-1}$ and $M_{2}$ and $S_{2}$ amplitudes change with rates of 0.4 and $0.2 \mathrm{~cm}$ decade $^{-1}$, respectively. Also, along the European coast and in the North Sea the change in tidal amplitude is nonnegligible relative to the present mean sea level trend. For example, at Cuxhaven, the $M_{2}$ and $S_{2}$ amplitudes change with rates of 1.1 and $0.4 \mathrm{~cm}$ decade ${ }^{-1}$, respectively, a trend which is comparable to the mean sea level trend of $1.8 \mathrm{~cm}$ decade $^{-1}$.

[33] For the same subset of stations as used in Figure 8 the sum of the trends of $M_{2}, S_{2}, K_{1}$ and $O_{1}$ is compared with the trend in mean sea level (Figure 9). The trends in tidal amplitude are mostly below $1 \mathrm{~cm}$ decade $^{-1}$, whereas the mean sea level trends are in the range from 1 to $3 \mathrm{~cm} \mathrm{decade}^{-1}$. Thus mean sea level trends are higher than the corresponding trends of the tidal amplitudes. However, since in certain coastal regions the changes of tidal amplitudes are still significant compared with the mean sea level trend it will be of considerable importance to include their changes in hazard assessment studies related to flooding risks and coastal erosion.

\section{Ocean Tide Model Sensitivity Experiments}

[34] One possible explanation for the tidal trends might be the ongoing change of water column thickness due to GIA or eustatic sea level rise. Although the last deglaciation phase of the ice age ended approximately 6000 years ago, the GIA process still leads to significant rates of sea level change in the present-day [e.g., Davis and Mitrovica, 1996; Peltier, 2004]. An important motivation for our focus on GIA here is the work of Greenberg et al. (submitted manuscript, 2011). 


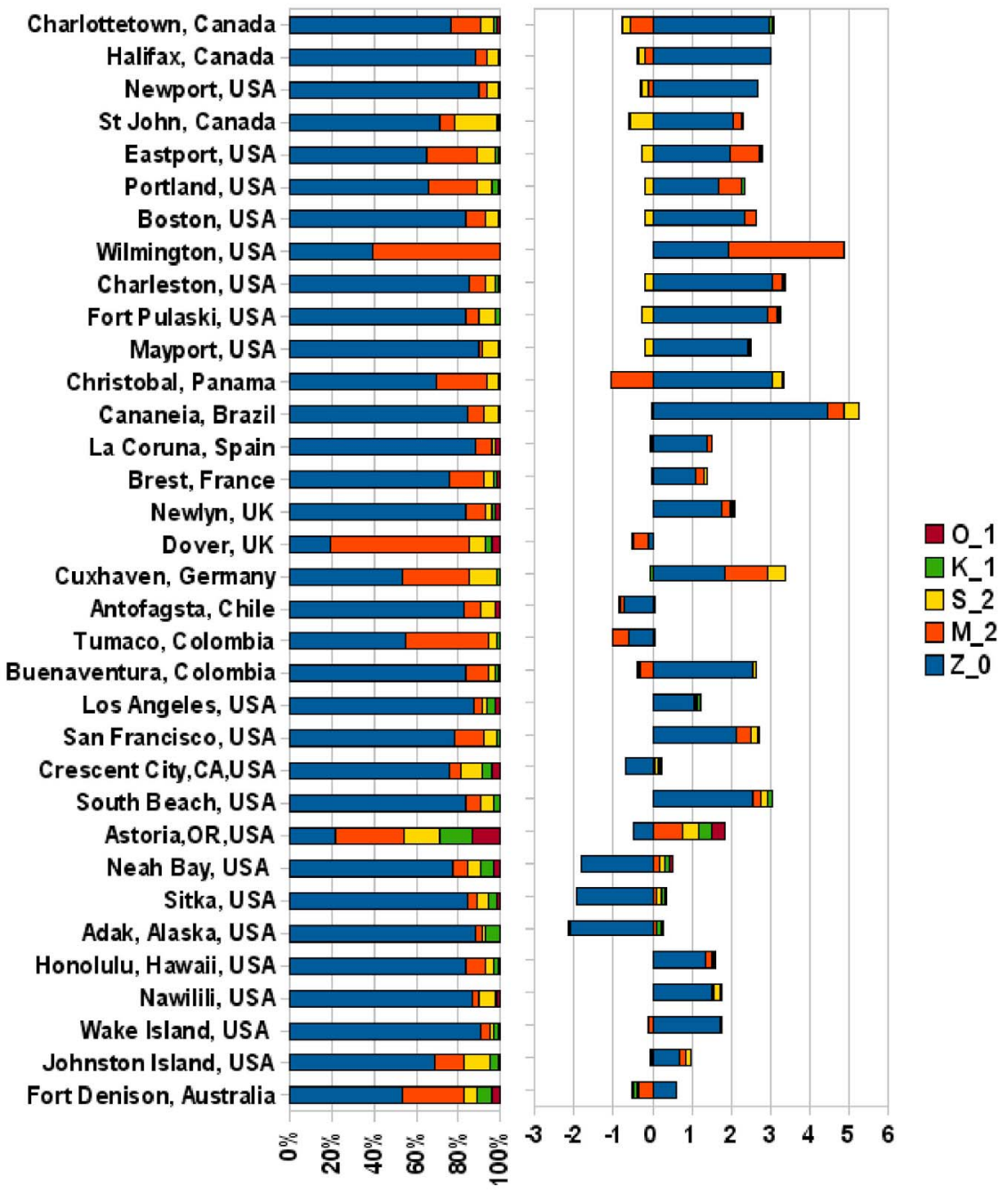

Figure 8. Comparison of the mean sea level trend and tidal trends at selected stations. (left) The sum of the amplitude trends of all analyzed tidal constituents $\left(M_{2}, S_{2}, K_{1}\right.$, and $\left.O_{1}\right)$ and the mean sea level trend $Z_{0}$ represents $100 \%$, and the contributions of each tidal constituent and the mean sea level is shown. (right) The absolute trends of each component in $\mathrm{cm}$ decade ${ }^{-1}$.

They used a regional tide model to demonstrate that the trends in the $M_{2}$ tide can be explained by the change in ocean bathymetry due to the GIA. Interestingly, the change in the tidal response within the Gulf of Maine seems not to be primarily caused by the modification of ocean depth in the Gulf itself, but rather through the depression of Georges Bank, offshore of the Gulf of Maine, with a rate of $\sim 25 \mathrm{~cm}$ century $^{-1}$. This suggests that tidal trends in other regions may be controlled by uplift or depression of the ocean bottom due to GIA processes.

[35] In the following, we will explore tidal sensitivity to GIA and to eustatic sea level rise, using the barotropic version of the forward numerical global tide model of Arbic et al. [2004]. As in the earlier paper, the model domain runs from $86^{\circ} \mathrm{S}$ to $82^{\circ} \mathrm{N}$, with an artificial wall at the northern boundary, and the topographic wave drag term is active only in waters deeper than $1000 \mathrm{~m}$. (We have found that activating topographic wave drag at all depths improves model accuracies slightly). We will explore changes in $M_{2}$ induced by GIA and eustatic sea level rise. We will utilize two different horizontal resolutions: $1 / 2^{\circ}$ and $1 / 8^{\circ}$. Consistent with the results of Egbert et al. [2004], we find that the model accuracy increases with increasing horizontal resolution. The $M_{2}$ control experiments (experiments done with presentday conditions), for example, yield an $M_{2}$ elevation error of $6.69 \mathrm{~cm}$ at $1 / 8^{\circ}$ resolution, and $8.02 \mathrm{~cm}$ at $1 / 2^{\circ}$ resolution. The errors are measured against the highly accurate GOT99 satellite-altimeter constrained tide mode [Ray, 1999], and computed in waters deeper than $1000 \mathrm{~m}$ and in latitudes equatorward of $66^{\circ}$, the turning points of the TOPEX/ POSEIDON altimeter. Furthermore, as noted by Arbic et al. [2008], more accurate high-resolution results can be obtained with a smaller "multiplicative factor" [Arbic et al., 2004]; we use 5 and 7 in the $1 / 8^{\circ}$ and $1 / 2^{\circ}$ runs, respectively. The multiplicative factor is a tunable factor accounting for deficiencies in our topographic wave drag scheme and in our knowledge of small-scale topographic roughness; smaller values are preferable. 


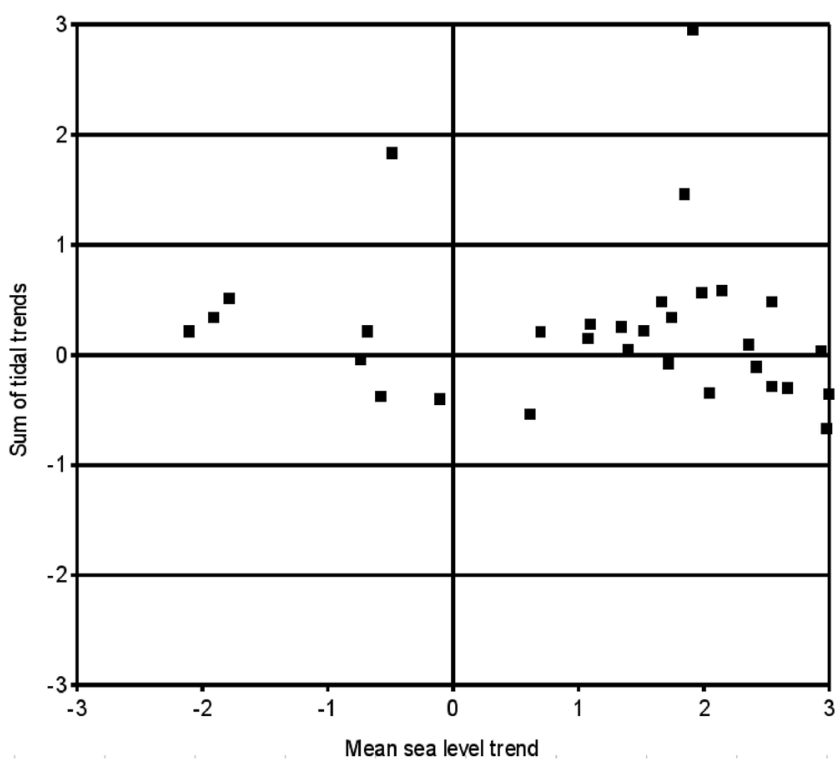

Figure 9. For the same selection of stations as in Figure 8, the sum of trends of $M_{2}, S_{2}, K_{1}$, and $O_{1}$ amplitudes are plotted versus the corresponding trend in mean sea level. The $x$ axis represents the mean sea level trends and the $y$ axis the tidal amplitude trends, both given in $\mathrm{cm}$ decade ${ }^{-1}$.

[36] Because the observed secular changes are small, for instance much smaller than the changes in tides seen between the ice ages and the present-day [e.g., Egbert et al., 2004], it will be important to monitor how stable the numerical model is to changes in horizontal resolution, iterations used to compute the self-attraction and loading (SAL) term, and so on. SAL [Hendershott, 1972] is an important term in tidal models. It consists of the self-gravitation of the ocean tide, the deformation of the solid earth due to the load of the ocean tide, and the self-gravitation of the solid earth thus deformed. Ocean tides are very sensitive to the SAL term since it affects the oceanic response by shifting the periods of the global free oscillations by up to $0.5 \mathrm{~h}$ toward higher values [Müller, 2007]. In the case of the resonant response of the ocean to the tidal forces, this can lead to large-scale modifications of tidal amplitudes and phases. The SAL term is cumbersome and expensive to calculate and is often modeled with an iterative procedure, where the first iteration is computed using the scalar approximation [Accad and Pekeris, 1978], and successive iterations use results from the full spherical harmonic machinery [Hendershott, 1972; Ray, 1998] applied off-line to the output from the previous iteration. In Figures $10 \mathrm{a}-10 \mathrm{c}$ we show the differences in $M_{2}$ amplitudes between iterations of the SAL term for our $1 / 8^{\circ} M_{2}$ control run. Our iteration procedure, as with Egbert et al. [2004], incorporates a term that forces the iterations to converge more rapidly. Consistent with the results of Egbert et al. [2004], the difference between iterations reduces as the number of iterations increases. However, differences exceeding $1 \mathrm{~cm}$ are still apparent in some areas even after several iterations. Since the secular changes we are looking for are sometimes of this order of magnitude, this is problematic. We are actively working to improve the forward model by computing the spherical harmonic terms inside the model as it is running [Zahel, 1980; Stepanov and Hughes, 2004], rather than through an iterative procedure utilizing off-line calculations. If this effort is successful, the iteration jitter will be removed, and future simulations of the forward global numerical model will be less cumbersome to run and to interpret.

\section{Sensitivity Experiments: Changes in Relative Sea Level}

[37] For the sensitivity experiments, we require maps of changes in water column thickness, or relative sea level. Relative sea level (RSL) refers to changes in sea surface height relative to the solid Earth. We may thus write

$$
R S L(t)=G(t)-R(t)
$$

where $G(t)$ is the sea surface height (i.e., absolute sea level) as a function of time $t$, and $R(t)$ is the change in the radial position of the solid surface as a function of time. A global map of $R(t)$ does not exist, and therefore it is difficult to insert reliable maps of the quantity of interest (RSL) into tide models. We may, however, utilize models of some components of the sea level signal into our tide model. For instance, we can compute from viscoelastic Earth models an estimate of the RSL due to GIA.

[38] Our predictions of the recent RSL change due to GIA were calculated using the pseudospectral algorithm described by Mitrovica and Milne [2003] and Kendall et al. [2005], with a truncation at degree and order 256. These calculations incorporate time-dependent shoreline migration due to both local onlap and offlap and the growth and ablation of grounded marine-based ice. They also include the feedback onto sea level of contemporaneous perturbations in the orientation and magnitude of the Earth's rotation vector. This perturbation was computed using the rotational stability theory described by Mitrovica et al. [2005]. The Earth models are self-gravitating and spherically symmetric, with a Maxwell viscoelastic rheology. For the latter we adopt the elastic and density structure of the seismically inferred model PREM [Dziewonski and Anderson, 1981].

[39] We consider results based on two different viscosity profiles. The first (GIA1) is the VM2 viscosity model derived by Peltier [2004], which is characterized by a moderate increase (by a factor of approximately 3 ) in viscosity with depth from the base of the lithosphere to the core-mantle boundary. The second (GIA2) is a profile that falls within the class of viscosity models preferred on the basis of various GIA data sets [e.g., Lambeck et al., 1998; Mitrovica and Forte, 2004]; specifically, it is composed of an elastic lithosphere of thickness $120 \mathrm{~km}$, an upper mantle viscosity of $5 \times$ $10^{20}$ Pas, and a lower mantle viscosity of $5 \times 10^{21}$ Pas. We note that this viscosity model has also been favored in terms of its ability to reconcile the geographic trends in tide gauge rates along the U.S. East Coast [Davis and Mitrovica, 1996]. Both viscosity profiles are paired with the ICE-5G deglaciation history [Peltier, 2004].

[40] Figure 11a is a map of the sea level change computed using the GIA2 model in units of $\mathrm{cm}$ century ${ }^{-1}$. The largest amplitude sea level fall occurs in Hudson Bay, Fennoscandia and parts of Antarctica; a sea level rise reaching $20-40 \mathrm{~cm}$ is predicted on the periphery of these regions. The relative sea 
(a) Iteration 4 - Iteration 3

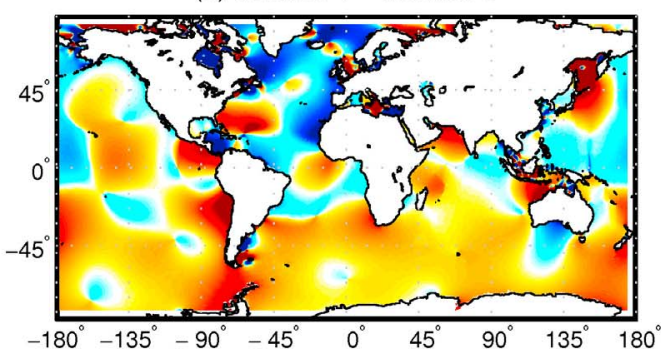

(b) Iteration 5 - Iteration 4

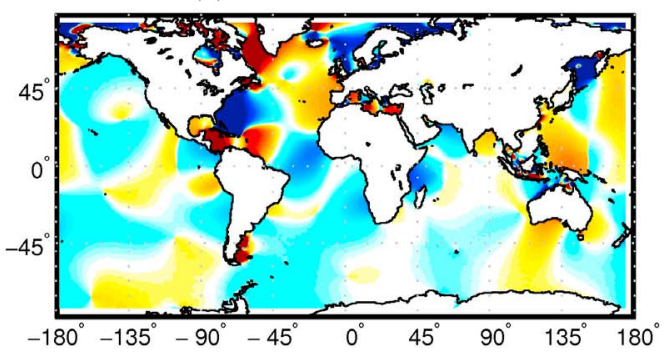

(c) Iteration 6 - Iteration 5

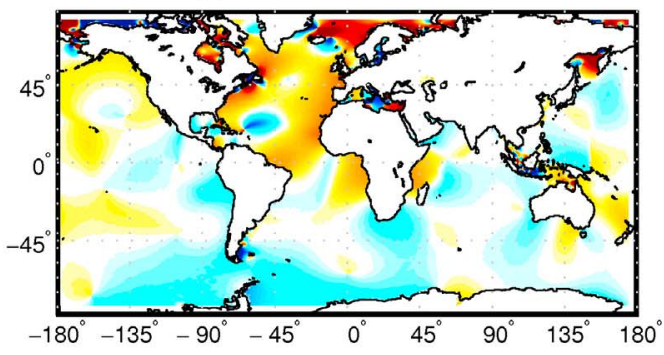

(d) Iteration 4 : control - GIA

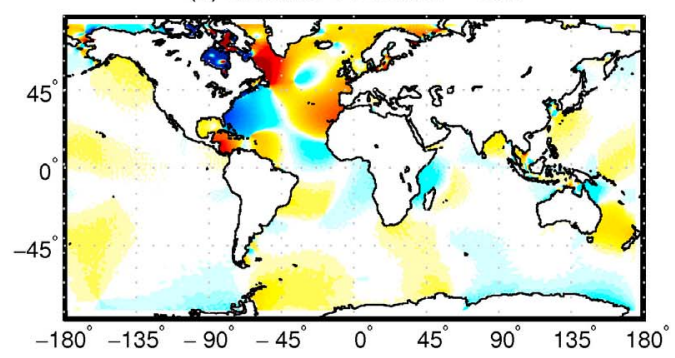

(e) Iteration 5 : control - GIA

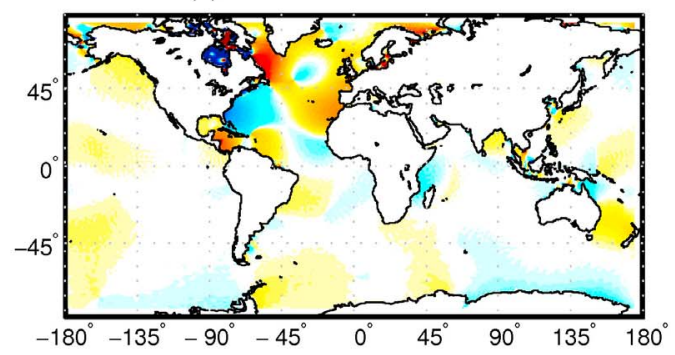

(f) Iteration $6:$ control - GIA

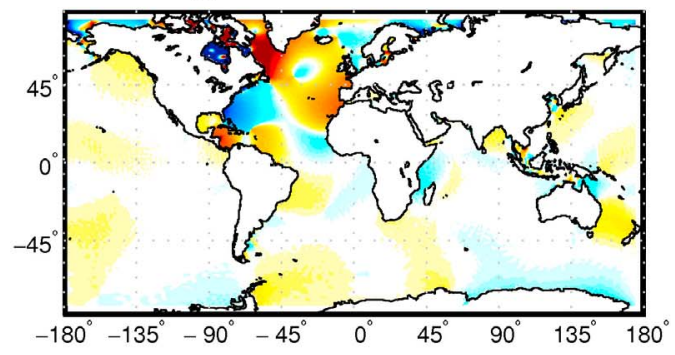

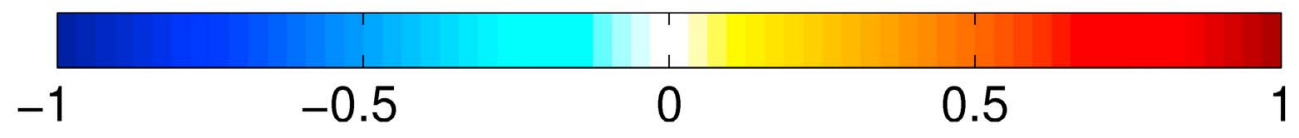

Figure 10. (a-c) Difference $(\mathrm{cm})$ in $M_{2}$ amplitudes between successive iterates of the SAL term, for the $1 / 8^{\circ} M_{2}$ control run (see text for details). The $x$ and $y$ axes represent longitude and latitude, respectively, in ${ }^{\circ} .(\mathrm{d}-\mathrm{f})$ Difference $(\mathrm{cm})$ in $M_{2}$ amplitudes between present and 100 years ago, assuming that the GIA shown in Figure 11a is the only change in relative sea level. Differences are shown for the fourth, fifth, and sixth iterations of the SAL term. See text for further explanation.

level 100 years ago, assuming that GIA is the only process acting, can be retrodicted by subtracting Figure 11a from the present-day relative sea level (or ocean bathymetry). This procedure yields not only a water column thickness 100 years ago, but also a revised shoreline (land-ocean mask) location, both of which are input into the ocean tide model. The tide model assumes a minimum water thickness of $1 \mathrm{~m}$; points shallower than this are identified as land points. After retrodicting using the GIA2 signal, the number of ocean model grid points that represent land differs from the number of grid points in the present-day model by approximately 1000 in case of the $1 / 8^{\circ}$ grid resolution (26 grid points at $1 / 2^{\circ}$ resolution). The locations of these grid points are mostly in Arctic regions and in the Baltic Sea where the GIA2 signal has large values. As shown in Arbic et al. [2009] and Arbic and Garrett [2010], forward ocean tide models are very sensitive to the "blocking" out of coastal regions, that is the migration of shorelines, especially if such regions are in resonance. Thus all indications are that the ocean tide model sensitivity to sea level changes is controlled in part by changes in the landocean mask as well as by changes in water column thickness (RSL). Note that the inferences of model sensitivity to migrating shorelines by Arbic et al. [2009] and Arbic and Garrett [2010] were taken from coarse resolution simulations $\left(1 / 2^{\circ}\right)$, in which shelves are not always well resolved. However, all indications are that the sensitivity to shoreline migrations in $1 / 2^{\circ}$ models are not completely dissimilar to the sensitivity in $1 / 8^{\circ}$ models. With Arbic et al. [2009] (see their Figures 10-13) the coastal tides in $1 / 2^{\circ}$ models compare reasonably well with observations. Since even $1 / 2^{\circ}$ models can capture coastal tides with some amount of accuracy, their sensitivity to shoreline migrations is likely to be reasonable. With Arbic et al. [2008; see also Egbert et al., 2004], the difference between modeled tides of the ice ages and of 
(a) GIA2

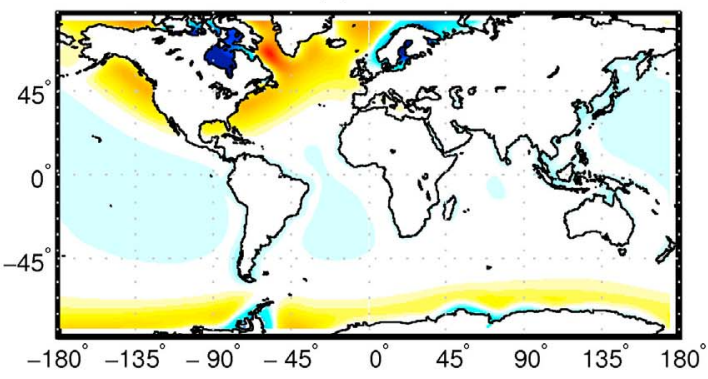

(b) Church et al.

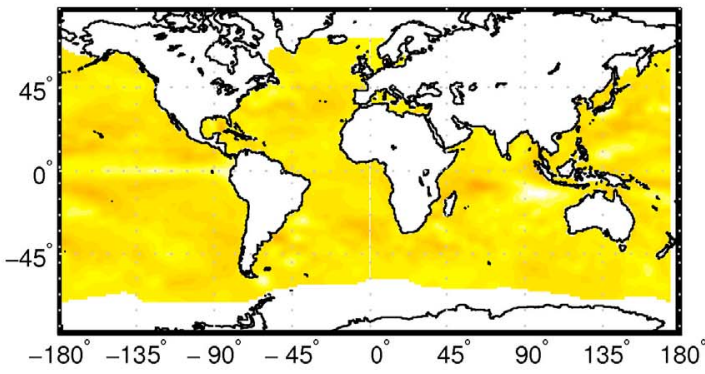

(c) Colorado with IB

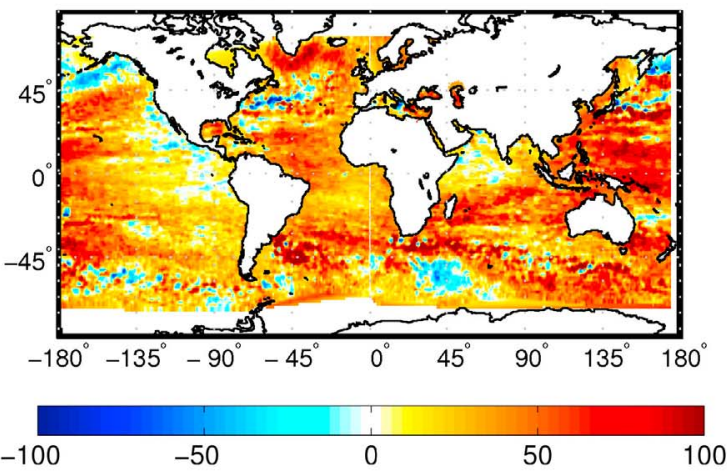

(d) control - GIA2

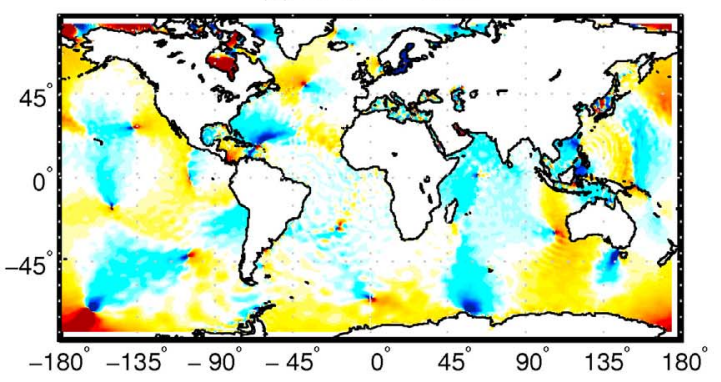

(e) control - Church et al.

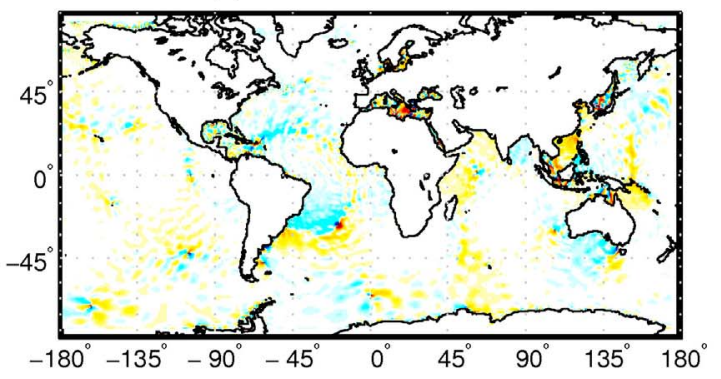

(f) control - Colorado with IB

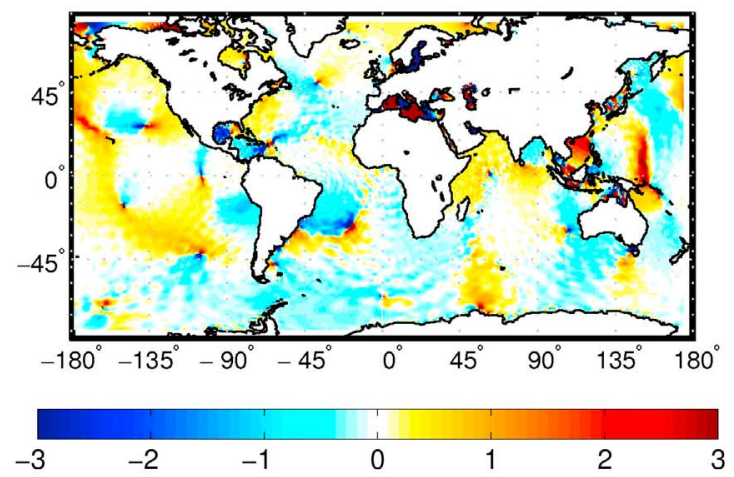

Figure 11. Differences $(\mathrm{cm})$ in relative sea level over 100 years, based upon (a) the GIA signal computed using the GIA2 model described in the text, (b) results from Church et al. [2004], and (c) data from the Web site http://sealevel.colorado.edu. (d-f) Change of $M_{2}$ amplitudes in \% between present-day and 100 years ago, where relative sea level on a $1 / 2^{\circ}$ grid is based on Figures $11 \mathrm{a}-11 \mathrm{c}$, respectively.

the present is captured reasonably well in $1 / 2^{\circ}$ simulations; the results do not change appreciably when the resolution is increased to $1 / 8^{\circ}$. All of this suggests that the sensitivity to shoreline migrations found in the $1 / 2^{\circ}$ simulations of Arbic et al. [2009] and related papers is likely to hold in $1 / 8^{\circ}$ simulations.

[41] The sensitivity of the amplitudes in $1 / 8^{\circ} M_{2}$ simulations to the 100 year GIA2 changes are displayed in Figures $10 \mathrm{~d}-$ 10f. We show differences for iterations 4 through 6 . In other words, we subtract iteration 4 of the 100 year ago run from iteration 4 of the control run. Then we subtract iteration 5 from iteration 5, and so on. Although the differences between successive iterations of the same simulation can be large (Figures 10a-10c), differences between the present and past runs shown in Figures 10d-10f are relatively consistent as long as the same iteration number is used. This procedure seems to bypass some of the problems displayed in Figures 10a-10c ("iteration jitter"); however, the subplots in Figures 10d-10f are not identical, meaning that the "iteration jitter" is still problematic. We performed this sensitivity experiment with calculations based on GIA1, as well, which yielded similar results (not shown) to those for GIA2.

[42] In addition to the GIA results, we have considered several other estimates of sea level change. However, because $1 / 8^{\circ}$ ocean tide simulations are computationally expensive (about 13 wall clock h on 72 processors of the Florida State University high-performance computing cluster, per iteration of the one-layer model), we performed these other explorations at lower horizontal resolution $\left(1 / 2^{\circ}\right)$. To further decrease the computational requirements, we performed only four iterations of the SAL term, not 6 as in Figure 10. For example, we used three other sea level maps derived, in whole or in part, from satellite altimetry constraints to retrodict tides. The first such map, from Church et al. [2004], was derived by 
(a) GIA2 1/8

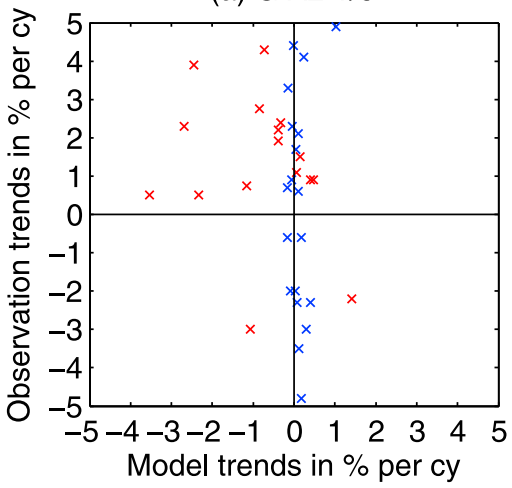

(c) Colorado with IB $1 / 2$

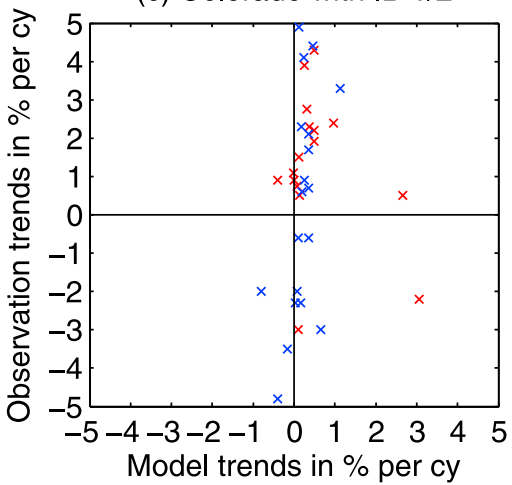

(b) GIA2 1/2

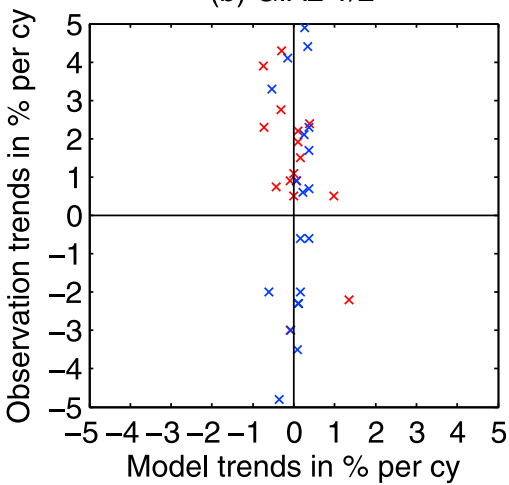

(d) Church et al. $1 / 2^{\circ}$

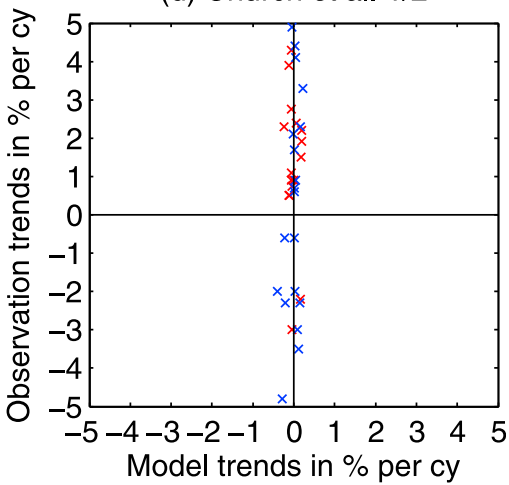

Figure 12. Comparison of the model sensitivity experiments with the observational $M_{2}$ amplitude trends. Blue (red) $x$ display stations in the Pacific (Atlantic). The $y$ axes show the observed trends of the $M_{2}$ amplitudes (in $\%$ century $^{-1}$ ). The $x$ axes show the difference of the $M_{2}$ amplitudes (in \%) of the control experiment and the sensitivity experiment on the $1 / 8^{\circ}$ model grid using (a) the GIA 2 map, and on the $1 / 2^{\circ}$ model grid, using (b) the GIA2 map, (c) the UColorado map, and (d) the Church et al. [2004] map.

inferring the spatial variation in sea surface height from altimetry data using an empirical orthogonal function analysis and then using tide gauge data from 1950 onward to estimate the amplitude time series for the first few EOFs (an inverted barometer correction was also applied). The second and third, downloaded from http://sealevel.colorado.edu (2008 Release 2) [see also Leuliette et al., 2004], were based entirely on altimetry data over the last two decades (with and without an IB correction applied). Therefore, although these are maps of absolute, rather than RSL, we interpret them as the latter for the sake of this sensitivity study. As before, we use the maps to retrodict sea level and the shoreline location 100 years ago. Figures $11 \mathrm{~b}$ and $11 \mathrm{c}$ show sea level changes over 100 years computed from the Church et al. [2004] and University of Colorado (IB correction applied) maps (UColorado), respectively. Note that the Church et al. [2004] map had less impact on the land-ocean mask than the UColorado map, and the latter had less impact than the GIA2 map. Figures 11d-11f show the changes in $M_{2}$ amplitudes between tidal runs at present-day and 100 years ago for all three cases described above: GIA2, Church et al. [2004] and UColorado (all runs based on a $1 / 2^{\circ}$ grid). We first note that results for the GIA2 case differ quantitatively from analogous results performed on a $1 / 8^{\circ}$ grid. Therfore horizontal resolution must therefore be added to "iteration jitter" as an issue of importance for global tidal simulation comparisons over century time scales. (This situation is in contrast to ice age tide simulations, where sea level changes are much larger and the computed paleotidal responses are consistent for calculations based on several different GIA model groups (see, e.g., references on ice-age tide studies given by Arbic et al. [2009] and Arbic and Garrett [2010]).)

[43] In any event, results in Figure 11 indicate a sensitivity of the tide to changes in water column thickness across the 20th century. Calculations based on the Church et al. [2004] sea level map show the least sensitivity; this is likely due to the fact that adoption of the first few EOFs of the satellite altimetry field acts, in practice, to filter out short wavelengths (see Figure 11b). A quantitative comparison of the model results and the observations is shown in Figures 12 and 13. There, the trends of $M_{2}$ amplitude and phase for each tide gauge record, which were analyzed in section 3 , are compared with the corresponding result of the above mentioned sensitivity experiments. In Figures 12 and 13 the displayed ranges are limited to $\pm 5 \%$ century $^{-1}$ and $\pm 5^{\circ}$ century $^{-1}$ for amplitude and phase trends, respectively. Thus, in Figure 12 twelve stations and in Figure 13 ten stations are off the scale. For the same reason, in case of the North Atlantic three stations are not displayed in Figures 12 and 13. One of them is Wilmington which has extraordinary large amplitude and phase trends, which are likely caused by local factors (see section 3 ) and are not expected to appear in the model results. Increasing the scale of Figures 12 and 13 would make it difficult to distinguish between the majority of stations which 
(a) GIA2 1/8

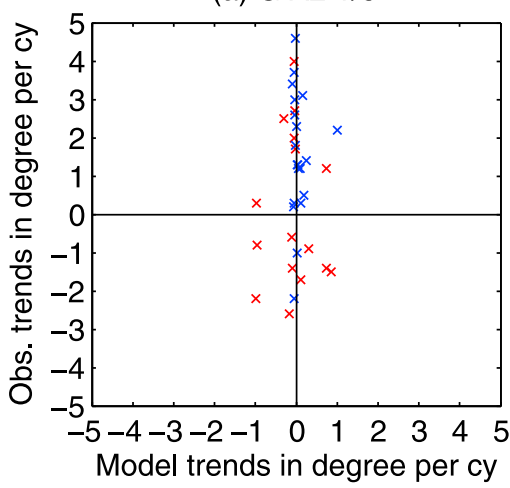

(c) Colorado with IB $1 / 2$

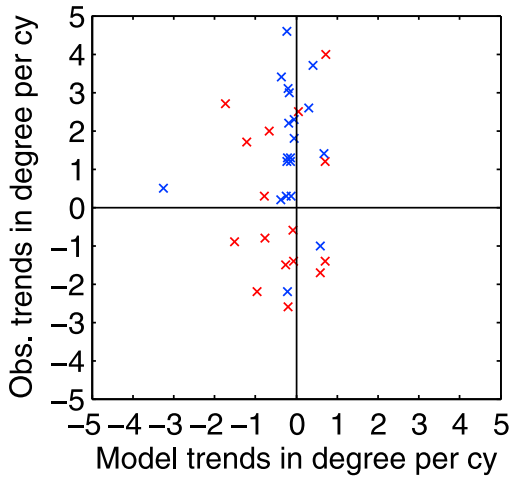

(b) GIA2 1/2

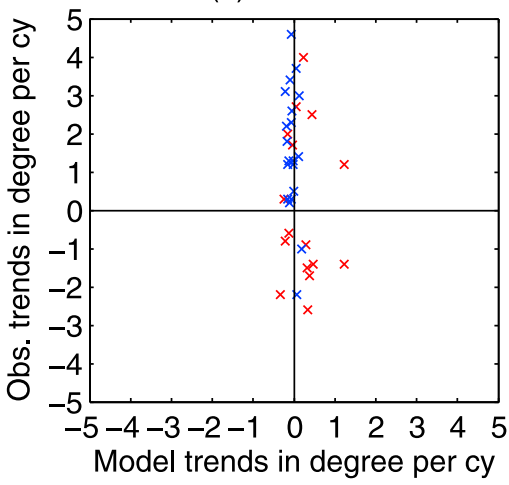

(d) Church et al. $1 / 2^{\circ}$

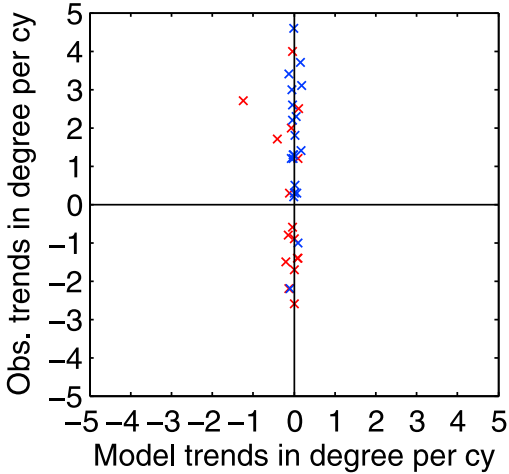

Figure 13. Comparison of the model sensitivity experiments with the observational $M_{2}$ phase trends. Blue (red) $x$ display stations in the Pacific (Atlantic). The $y$ axes show the observed trends of the $M_{2}$ phase (in ${ }^{\circ}$ century $^{1}$ ). The $x$ axes show the difference of the $M_{2}$ phases (in ${ }^{\circ}$ ) of the control experiment and the sensitivity experiment on the $1 / 8^{\circ}$ model grid using (a) the GIA2 map, and on the $1 / 2^{\circ}$ model grid, using (b) the GIA2 map, (c) the UColorado map, and (d) the Church et al. [2004] map.

have trends of around $1-4 \%$ century $^{-1}$ and $1-4^{\circ}$ century $^{-1}$. In order to have a more objective measure to compare model results and observations, root-mean-square (RMS) values of the trends in amplitude and phase are computed (Table 3), where all analyzed tide gauge stations (except Wilmington) are considered.

[44] The tide model experiment on the $1 / 8^{\circ}$ grid using the GIA2 map shows a sensitivity in $M_{2}$ amplitudes (Figure 12) in the North Atlantic of similar magnitude as the observed trends, however, the values have mostly opposite signs. The RMS values indicate that the magnitude of the North Atlantic amplitude trends in this particular model simulation is about $44 \%$ of that of the observations. The experiment with the UColorado map yields a RMS value of the amplitude trends in the North Atlantic of similar size. The sensitivity in the $M_{2}$ phase (Figure 13) is largest in the experiment with the UColorado map, and once again only the North Atlantic shows similar magnitudes as those in the data, where the RMS value of the model result with the UColorado map is $32 \%$ of the value of the observations. In general, the sensitivity of the $M_{2}$ tide amplitudes and phases in the Pacific is significantly lower than the corresponding observed trends. The simulated magnitudes of changes of the tidal amplitude and phases in the Pacific are only about 10-20\% compared with the observed ones. These results indicate that GIA and eustatic sea level rise may be important contributors to the observed trends in the North Atlantic. However, due to the problems of "iteration jitter" and grid resolution, quantitative predictions are currently difficult.

\section{Understanding the GIA2 Sensitivity Experiment in Terms of Free Oscillations}

[45] In this section, we analyze the results of the GIA2 sensitivity experiment $\left(1 / 8^{\circ}\right.$ model grid) of section 6 as

Table 3. RMS Values of Observed and Simulated Trends in Amplitudes and Phases ${ }^{\mathrm{a}}$

\begin{tabular}{|c|c|c|c|c|c|c|}
\hline & North Atlantic Amplitude & North Atlantic Phase & Pacific Amplitude & Pacific Phase & Global Amplitude & Global Phase \\
\hline Observations & 3.37 & 2.77 & 4.04 & 3.81 & 4.47 & 4.19 \\
\hline GIA2 $1 / 8^{\circ}$ & 1.46 & 0.53 & 0.44 & 0.32 & 1.10 & 0.41 \\
\hline GIA2 $1 / 2^{\circ}$ & 0.77 & 0.52 & 0.88 & 0.13 & 0.83 & 0.45 \\
\hline Colorado $1 / 2^{\circ}$ & 1.37 & 0.89 & 0.84 & 0.67 & 1.08 & 0.76 \\
\hline Church et al. [2004] 1/2 & 0.15 & 0.34 & 0.13 & 0.08 & 0.17 & 0.24 \\
\hline
\end{tabular}

${ }^{a}$ Amplitudes and phases are given in $\%$ century $^{-1}$ and ${ }^{\circ}$ century $^{-1}$, respectively. Trends at Wilmington are not considered. 


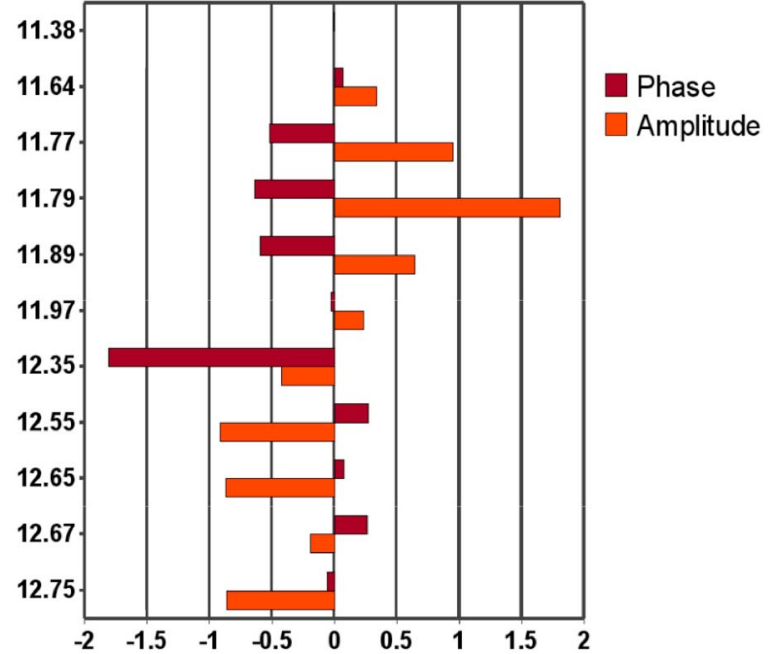

Figure 14. Decomposition of the control and GIA2 sensitivity experiment into global free oscillations. The $y$ axis refers to the eigenperiod $(\mathrm{h})$ of the respective free oscillations [Müller, 2009]. The $x$ axis shows the changes in the amplitude $\left(\bar{a}_{k}^{G I A 2}-\bar{a}_{k}^{\text {control }}\right) / \bar{a}_{k}^{\text {control }}$ (red bars) in \% and phase $\phi_{k}^{\text {GIII }}-\phi_{k}^{\text {control }}$ (orange bars) in ${ }^{\circ}$.

reflected by changes in the ocean's free oscillation system. For a decomposition of the model results into global free oscillations, we describe the global $M_{2}$ tide model solution $\mathbf{w}=(\zeta, u, v)$, where $\zeta$ is the sea surface elevation and $u$ and $v$ are horizontal velocities, as a superposition of eigenvectors $\mathbf{x}_{k}=\left(\zeta_{k}, u_{k}, v_{k}\right)$

$$
\mathbf{w}=\sum_{k=1}^{\infty} a_{k} \mathbf{x}_{k},
$$

with the complex expansion coefficients $a_{k}$. Applying the orthogonality relation

$$
\left\langle\mathbf{x}_{k}, \widehat{\mathbf{x}}_{l}\right\rangle=\delta_{k l},
$$

where $\widehat{\mathbf{x}}_{k}$ are the adjoint eigenvectors, yields for the expansion coefficients

$$
a_{k}=\left\langle\mathbf{w}, \widehat{\mathbf{x}}_{k}\right\rangle .
$$

[46] This synthesis approach is similar to that of Platzman [1984], with the difference that he used, due to the computational limits at that time, nondissipative free oscillations. In this case, the adjoint eigenvector $\widehat{\mathbf{x}}_{k}$ is simply the complex conjugate of the eigenvector $\mathbf{x}_{k}$. A special procedure has been used by Platzman [1984] to obtain estimates of the 'dissipative' expansion coefficients. In the approach of [Zahel and Müller, 2005] dissipative free oscillations have been used to estimate the magnitude of the expansion coefficients. They fitted the weighted sum of their free oscillations to tidal model solutions by means of least squares. Thus, it was not necessary to compute the adjoint eigenfunction. In contrast, the synthesis approach used in the present study utilizes dissipative ocean free oscillations and their adjoint counterparts. Thus, the expansion coefficients are explicitly given by (16). We refer to Müller [2008, 2009] for further information on the synthesis procedure. The biorthogonal system of eigenfunctions is computed on a global $1^{\circ}$ grid with explicit consideration of frictional effects and the full SAL effects, which are described by the Green's functions of loading and self-attraction [Francis and Mazzega, 1990]. Since we combine these free oscillations with the results from the Arbic et al. [2004] model, we assume that the oscillation system of the tide model can be described in good approximation by this free oscillation expansion. Of course, this assumption has its limits due to the two different model designs, nevertheless the approach enables us to understand sensitivities evident in tidal experiments in terms of free oscillations.

[47] We decompose the $1 / 8^{\circ}$ resolution model results in section 6 (control and GIA2) into free oscillations in the period range from 11 to $13 \mathrm{~h}$. The accuracy of the expansion coefficients is not dependent on the number of free oscillations included [Platzman, 1984; Zahel and Müller, 2005], but rather on the accuracy of the orthogonality relation (15), which is fulfilled with an error lower than $5 \times 10^{-7}$.

[48] Thus, we obtain two series of expansion coefficients $\left\{a_{k}\right\}^{\text {control }}$ and $\left\{a_{k}\right\}^{\text {GIA2 }}$ and further analyze these complex values in terms of their amplitudes $\bar{a}_{k}$ and phases $\phi_{k}$. The relative changes (in \%) of the respective amplitudes and phases, evident when GIA2 was inserted into the tide model, are shown in Figure 14. The plot shows a systematic change of the expansion coefficients with respect to the corresponding eigenperiod of the free oscillations. The amplitudes of the expansion coefficients for free oscillations with periods lower (higher) than $12 \mathrm{~h}$ are reduced (amplified) through the inclusion of the GIA2 signal, and the associated phases are mostly delayed (advanced).

[49] Further, in order to physically interpret the changes of the expansion coefficients, we consider the linearized tidal equations in general operator notation

$$
\frac{\partial \tilde{\mathbf{w}}}{\partial t}+\mathcal{L} \tilde{\mathbf{w}}=\tilde{\mathbf{F}}
$$

where $\tilde{\mathbf{F}}=\mathbf{F} e^{-i \sigma_{F} t}$ is the $M_{2}$ tidal forcing with the forcing frequency $\sigma_{F}$, the tidal solution is $\tilde{\mathbf{w}}=\mathbf{w} e^{-i \sigma_{F} t}$, and the operator $\mathcal{L}$ represents the tidal dynamics. We write (17) in spectral form

$$
\left(\mathcal{L}-i \sigma_{F}\right) \mathbf{w}=\mathbf{F} .
$$

[50] Since the free oscillations $\mathbf{x}_{k}$ are solutions of the homogeneous equation

$$
\left(\mathcal{L}-i \sigma_{k}\right) \mathbf{x}_{k}=0,
$$

we find an expression for the weighting coefficients by applying (14) and (15)

$$
a_{k}=\frac{1}{i\left(\sigma_{k}-\sigma_{F}\right)}\left\langle\mathbf{F}, \widehat{\mathbf{x}}_{k}\right\rangle .
$$

[51] Obviously, the expansion coefficients depend on the spatial coherence of the forcing field $\mathbf{F}$ and adjoint eigenvector $\widehat{\mathbf{x}}_{k}$, and on the distance from the complex $k$ th eigenfrequency $i \sigma_{k}=\sigma_{k, 1}+i \sigma_{k, 2}\left(\sigma_{k, 1}\right.$ and $\sigma_{k, 2}$ describe the 


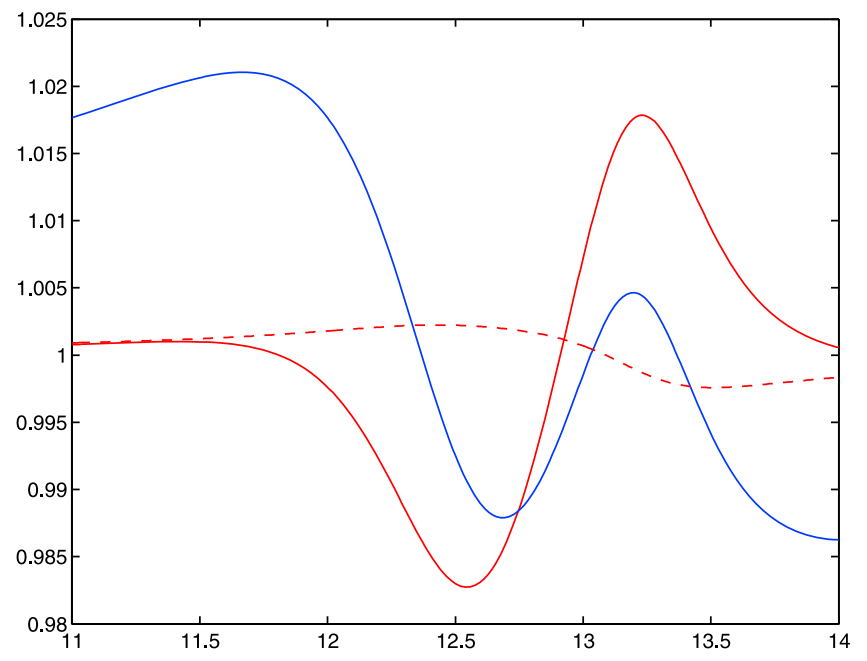

Figure 15. Results of the Arbic and Garrett [2010] coupled oscillator model. The eigenfrequency of the shelf and deep ocean are perturbed according to a change in depth of $1 \mathrm{~m}$ (see text for more details). The ratios of the tidal responses to modified versus unmodified ocean depth is shown. Solid blue (red) line depicts the response of the shelf (deep ocean) in the case of $\mathrm{a}+1 \mathrm{~m}$ increase in the depth of the shelf. Dashed red line depicts the changing response of both, shelf and deep ocean, in case of a $1 \mathrm{~m}$ increase in depth of the deep ocean. The $y$ axis displays the quantity $A_{1} / A_{0}$, where $A_{0}\left(A_{1}\right)$ is the tidal response to unmodified (modified) ocean depth. The $x$ axis is forcing period in $\mathrm{h}$.

damping and oscillatory component, respectively) to the forcing frequency $\sigma_{F}$. We assume that the GIA2 signal does not significantly change the spatial pattern of the free oscillations, but rather their eigenfrequencies. Thus, we attribute any modifications of the expansion coefficients to changes in the first part of (20), and rewrite it in terms of amplitude $R$ and phase $\varphi$

$$
\begin{gathered}
\frac{1}{i\left(\sigma_{k}-\sigma_{F}\right)}=R \exp (i \varphi) \\
\varphi=\arctan \left(\frac{\sigma_{F}-\sigma_{k, 2}}{\sigma_{k, 1}}\right), \\
R=\frac{1}{\sqrt{\sigma_{k, 1}^{2}+\left(\sigma_{k, 2}-\sigma_{F}\right)^{2}}}
\end{gathered}
$$

[52] Our results in Figure 14 show that perturbations to the amplitudes of the expansion coefficients are all negative (positive) for $\sigma_{F}>\sigma_{k, 2}\left(\sigma_{F}<\sigma_{k, 2}\right)$ and (22) indicates that the inclusion of the GIA2 signal leads generally to an increase of the oscillatory component $\left(\sigma_{k, 2}\right)$ of the eigenfrequency. Further, the phase changes are mainly positive (negative) for $\sigma_{F}>\sigma_{k, 2}\left(\sigma_{F}<\sigma_{k, 2}\right)$, whereas this pattern and (21) indicate a decreasing damping component $\left(\sigma_{k, 1}\right)$ when the GIA2 signal is included. An exception is the amplitude and phase change of the $12.35 \mathrm{~h}$ mode, presumably due to its near resonance. We can quantitatively estimate these changes from (21) and (22). In the case of the $11.77 \mathrm{~h}$ mode, one of the major contributors to the $M_{2}$ tide, the eigenperiod changes by $0.02 \%$ and the decay time $T_{D}\left(=1 /\left(2 \sigma_{k, 1}\right)\right)$ by $2.3 \%$. In summary, the free oscillation synthesis shows that the ongoing GIA2 signal leads to a shift of the eigenperiods toward smaller periods and to an increasing damping in the system.

\section{Changes in RSL and the Tidal Response of the Shelf and Deep Ocean}

[53] The results of sections 6 and 7 give rise to the question of how changes in RSL modify the ocean's tidal response. In the following, we use a simplified oscillator model of the coupled shelf and deep ocean in order to gain deeper insight into the results of sections 6 and 7.

[54] The GIA2 signal induces changes in depth of around $50-100 \mathrm{~cm}$, particularly in the North Atlantic (Figure 11a). We assume that the frequency of a free oscillation is proportional to $\sqrt{g H}$, where $g$ is the gravitational constant and $H$ the ocean depth. Thus in the deep ocean $(H \sim 4000 \mathrm{~m})$ a change of $1 \mathrm{~m}$ leads to a perturbation in the eigenfrequency of $\sim 0.0125 \%$. In contrast, in shallow waters $(H \sim 200 \mathrm{~m})$ this sea level change leads to a perturbation of $\sim 0.25 \%$.

[55] We use the coupled oscillator model of shelf and ocean tides [Arbic and Garrett, 2010] to analyze the impact of these changes in eigenfrequency on the tidal response of the shelf and deep ocean. The response of the ocean and shelf is given in their equations (13) and (14), respectively. The same parameter values are applied, i.e., a resonant period of $12.7 \mathrm{~h}(13 \mathrm{~h})$, a damping factor $\delta_{2}=0.14\left(\delta_{1}=\right.$ 0.02 ) for the shelf (deep ocean), and a coupling parameter $\epsilon=0.006$.

[56] We compute the tidal response (dependent on the forcing period) of the shelf and deep ocean in this coupled analytical model. Three different scenarios are chosen: (1) a control experiment with the parameter setup described above, (2) a perturbed resonant period of the shelf by $\sim 0.25 \%$, and (3) a perturbed resonant period of the deep ocean by $\sim 0.0125 \%$. In Figure 15 the relative deviation of experiments (2) and (3) to the control experiment (1) are shown. Note, that in case of experiment (3) the change in the resonant period of the deep ocean results in an identical relative response deviation of the shelf and deep ocean.

[57] These experiments show that a change of the eigenfrequency by $\sim 0.0125 \%$ (according to a $1 \mathrm{~m}$ change of the depth of the deep ocean) leads to a modification of the response of $<0.5 \%$ in amplitude (Figure 15) and cannot explain the changes evident in the sensitivity experiments (Figure 11). In contrast, changing the eigenfrequency by $\sim 0.25 \%$ (according to a $1 \mathrm{~m}$ change of the depth of the shelf) is, however, more effective in changing the response. Indeed, such changes can lead to a modification in the tidal response of the shelf of $1-2 \%$ in amplitude and a back effect on the deep ocean response of similar size.

[58] The one-dimensional coupled deep ocean/shelf model of Arbic et al. [2009], which solves the shallow water equations, yields results similar to those of the coupled oscillator model of Arbic and Garrett [2010] described above. Perturbing the depth of a $200 \mathrm{~m}$ shelf by $1 \mathrm{~m}$ in the one-dimensional shallow water model (baseline parameters taken as in their Figure 5, with the forcing frequency set to the $M_{2}$ frequency) also leads to order $1 \%$ changes in tidal 
amplitude in both deep ocean and shelf regions, as well as to order $1^{\circ}$ perturbations in phase.

\section{Summary and Conclusion}

[59] Over the last century, ocean tides have been evolving on a global scale with rates that cannot be explained by changes in gravitational forcing. The observed changes of ocean tide amplitudes and phases are either caused by local changes (e.g., harbor reconstructions, dredging out of river deltas, changes in the outflow of rivers) or by large-scale changes (e.g., stratification, bathymetry, ice cover, sea level) in the ocean system. In order to obtain an estimate of changes in the large-scale response of the global ocean to the tidal forcing, it is necessary to analyze a sufficient number of longterm time series. Unfortunately, such data sets are not available for all regions (Indian Ocean, Southern Hemisphere, and Arctic) of the global ocean. In the present study, we extended previous studies of several ocean regions [Cartwright, 1974; Woodworth et al., 1991; Flick et al., 2003; Ray, 2006, 2009; Jay, 2009] by analyzing a large number of stations to infer changes in amplitude and phase of the $M_{2}, S_{2}, K_{1}$, and $O_{1}$ tidal constituents. While preparing this manuscript we learned of an independent study by Woodworth [2010], Proudman Oceanographic Laboratory, UK, who compiled a spatially denser and more globally distributed set of records at 220 stations by including shorter records of at least 30 years length.

[60] The present study, has identified several regions which exhibit changes in the large-scale response of the ocean to the tidal forces. Perhaps the most notable of these regions is the North American Atlantic coast, where we infer uniform negative and positive amplitude trends in the $S_{2}$ and $K_{1}$ tidal constituents, respectively, accompanied by consistent phase changes. However, there are other regions where tidal trends in amplitude show consistent patterns, e.g., in the middle of the Pacific or along the North American Pacific coast. The fractional $S_{2}$ amplitude trends are, in most regions, significantly larger than the trends estimated for other constituents. These $S_{2}$ trends are up to $2 \%$ decade $^{-1}$ and positive, except for the North Atlantic coast, where trends are consistently negative but of the same order. These large-scale $S_{2}$ trends may reflect changes in the radiational forcing and, in this regard, an interesting task for future work would be to separate the gravitational and radiational ocean responses [Munk and Cartwright, 1966].

[61] We analyzed the sensitivity of a global barotropic tide model to changes in ocean depth caused by GIA and also allowed for present-day changes in mean sea level. Incorporating GIA into the tide model (with the high-resolution $1 / 8^{\circ}$ grid) or eustatic sea level rise (UColorado map) yielded perturbations in the modeled tidal amplitudes of the North Atlantic which amount to $40 \%$ of the magnitude as those evident in the observations. Further, tidal phases in the Atlantic show a sensitivity to eustatic sea level rise (UColorado map) with magnitudes of about $30 \%$ of the observed trends. However, these modeled changes do not all agree in sign with the observations. In general, the sensitivity experiments show for the Pacific $M_{2}$ tide significantly lower changes, compared to those seen in the observations. Since the model results display a dependence on horizontal resolution and iterations adopted in the SAL term, accurate predictions of secular tidal changes will require sufficiently high spatial resolution and a more robust representation of the SAL term.

[62] In addition to changes in the height of the water column due to GIA or mean sea level rise other possible reasons for the observed tidal trends may include:

[63] 1. Variations in atmospheric dynamics induced by climate change, which will lead to modifications in radiational and wind forcing which, in turn, will perturb tides at specific frequencies (e.g., $S_{2}$ and $K_{2}$ ).

[64] 2. Modifications of the internal wave field, and thus also of the surface tide, implied by changes in stratification, as observed at Honolulu, Hawaii [Colosi and Munk, 2006].

[65] 3. Seasonal changes of the ocean's stratification, between well mixed conditions in winter and stratified conditions in summer; Kang et al. [2002] have shown the importance of seasonality in their study of the China Sea, where variations in tidal amplitude of $\sim 10 \%$ are observed. Thus, it may be that, at least on the continental shelves, similar processes are responsible for a slight increase in tidal amplitude.

[66] 4. Changes in the ocean circulation, which may influence tides through nonlinear effects,

[67] 5. Changes in the extent of Arctic ice can have an impact on the tidal response in lower latitudes [Arbic et al., 2009; Arbic and Garrett, 2010].

[68] 6. Replacements of older tide gauges by newer technology could have an impact on the measured amplitudes and phases, as seen at several stations along the South African coast, where presumably the exchange of the float tide gauges by acoustic tide gauges appears to have resulted in an offset of the tidal amplitudes.

[69] The modeling of changing tides is a challenging technical problem and improvements in existing models will be necessary to perform a broader suite of sensitivity experiments. Identifying the underlying cause(s) for the changes in ocean tides is important since the trends in tidal amplitudes are significant compared to trends in mean sea level. Impact studies that deal with the protection of coastal zones from changes in sea level could thus benefit from robust predictions of the mean tidal range. Furthermore, if changes in tides are associated with climate change processes, then long-term sea level records may contain information concerning the evolving climate of the last century.

[70] Acknowledgments. This research is supported by a DFG (Deutsche Forschungsgemeinschaft) grant MU3009/1-1 to M.M., U.S. National Science Foundation grant OCE-0924481 to B.K.A., and support from Harvard University and the Canadian Institute For Advanced Research to J.X.M. We are grateful for the helpful discussions and comments from Chris Garrett. Further, the authors thank Peter Brominski, Gary Egbert, Ron Flick, Mike Foreman, Dave Greenberg, Myrl Hendershott, and Richard Ray for discussions. We thank the University of Hawaii Sea Level Center, the British Oceanographic Data Centre, and the Canadian Tides and Water Levels Data Archive for providing access to the sea level records. Numerical model computations were performed on the high-performance supercomputing cluster (HPC) at Florida State University. B.K.A. thanks Joey Molinari, Jordan Yao, Dan Voss, and Paul van der Mark for technical support on the HPC. We thank two anonymous reviewers for their careful reading of the manuscript.

\section{References}

Accad, Y., and C. L. Pekeris (1978), Solution of the tidal equations for the $M_{2}$ and $S_{2}$ tides in the world oceans from a knowledge of the tidal potential alone, Philos. Trans. R. Soc. London A, 290, 235-266. 
Arbic, B. K., and C. Garrett (2010), A coupled oscillator model of shelf and ocean tides, Cont. Shelf Res., 30, 564-574, doi:10.1016/j.csr. 2009.07.008.

Arbic, B. K., S. T. Garner, R. W. Hallberg, and H. L. Simmons (2004), The accuracy of surface elevations in forward global barotropic and baroclinic tide models, Deep Sea Res. Part II, 51, 3069-3101.

Arbic, B. K., J. X. Mitrovica, D. R. MacAyeal, and G. A. Milne (2008), On the factors behind large Labrador Sea tides during the last glacial cycle and the potential implications for Heinrich events, Paleoceanography, 23, PA3211, doi:10.1029/2007PA001573.

Arbic, B. K., R. H. Karsten, and C. Garrett (2009), On tidal resonance in the global ocean and the back-effect of coastal tides upon open-ocean tides, Atmos.-Ocean, 47, 239-266, doi:10.3137/OC311.2009.

Brosche, P., and J. Sündermann (1978), Tides around Pangaea, Naturwissenschaften, 64, 89-90.

Cartwright, D. E. (1971), Tides and waves in the vicinity of Saint Helena, Philos. Trans. R. Soc. London A, 270, 603-646.

Cartwright, D. E. (1974), Secular changes in the oceanic tides at Brest, Geophys. J. R. Astrol. Soc., 30, 433-449.

Church, J. A., N. J. White, R. Coleman, K. Lambeck, and J. X. Mitrovica (2004), Estimates of the regional distribution of sea level rise over the 1950-2000 period, J. Clim. 17, 2609-2625.

Colosi, J. A., and W. Munk (2006), Tales of the venerable Honolulu tide gauge, J. Phys. Oceanogr., 36, 967-996.

Davis, J. L., and J. X. Mitrovica (1996), Glacial isostatic adjustment and the anomalous tide gauge record from eastern North America, Nature, 379, 331-333.

Dziewonski, A. M., and D. L. Anderson (1981), Preliminary reference Earth model, Phys. Earth Planet. Inter., 25, 297-356.

Egbert, G. D., A. F. Bennett, and M. G. G. Foreman (1994), TOPEX POSEIDON tides estimated using a global inverse model, J. Geophys. Res., 99, 24,821-24,852.

Egbert, G. D., R. D. Ray, and B. G. Bills (2004), Numerical modeling of the global semidiurnal tide in the present day and in the last glacial maximum, J. Geophys. Res. 109, C03003, doi:10.1029/2003JC001973.

Flick, R. E., J. F. Murray, and L. C. Ewing (2003), Trends in United States tidal datum statistics and tide range, J. Waterway Port Coastal Ocean Eng., 129, 155-164.

Foreman, M. G. G. (1977), Manual for tidal heights analysis and prediction, Pac. Mar. Sci. Rep. 77-10, 58 pp., Inst. of Ocean Sci., Sidney, B. C., Canada.

Francis, O., and P. Mazzega (1990), Global charts of ocean tide loading effects, J. Geophys. Res., 95, 411-424.

Hendershott, M. C. (1972), The effects of solid earth deformation on global ocean tides, Geophys. J. R. Astron. Soc., 29, 389-402.

Hollebrandse, F. A. P. (2005), Temporal development of the tidal range in the southern North Sea, M.S. thesis, Delft Univ. of Technol., Delft Netherlands.

Jay, D. A. (2009), Evolution of tidal amplitudes in the eastern Pacific Ocean, Geophys. Res. Lett., 36, L04603, doi:10.1029/2008GL036185.

Kang, S. K., M. G. G. Foreman, H.-J. Lie, J.-H. Lee, J. Cherniawsky, and K.-D. Yuml (2002), Two-layer tidal modeling of the Yellow and East China seas with application to seasonal variability of the $\mathrm{M}_{2}$ tide, $\mathrm{J}$. Geophys. Res., 107(C3), 3020, doi:10.1029/2001JC000838.

Kendall, R., J. X. Mitrovica, and G. A. Milne (2005), On post glacial sea-level: Part II. Numerical formulation and comparative results on spherically-symmetric Earth models, Geophys. J. Int., 161, 679-706.

Ku, L. F., D. A. Greenberg, C. J. R. Garrett, and F. W. Dobson (1985), Nodal modulation of the lunar semidiurnal tide in the Bay of Fundy and Gulf of Maine, Science, 230, 69-71.

Lambeck, K., C. Smither, and P. Johnston (1998), Sea level change, glacial rebound and mantle viscosity for northern Europe, Geophys. J. Int., 134 , $102-144$.
Leuliette, E. W., R. S. Nerem, and G. T. Mitchum (2004), Calibration of TOPEX/Poseidon and Jason altimeter data to construct a continuous record of mean sea level change, Mar. Geod., 27, 79-94.

Maskelyne, N. (1762), Observations on the tides in the island of St. Helena, Philos. Trans. R. Soc. London, 52, 586-606.

Melchior, P. (1978), The Tides of the Planet Earth, 609 pp., Pergamon, Oxford, U. K.

Mitrovica, J. X., and A. M. Forte (2004), A new inference of mantle viscosity based upon a joint inversion of convection and glacial isostatic adjustment data, Earth Planet. Sci. Lett., 225, 177-189.

Mitrovica, J. X., and G. A. Milne (2003), On post-glacial sea-level: Part I. General theory, Geophys. J. Int., 154, 253-267.

Mitrovica, J. X., J. Wahr, I. Matsuyama, and A. Paulson (2005), The rotational stability of an ice-age Earth, Geophys. J. Int., 161, 491-506.

Müller, M. (2007), The free oscillations of the world ocean in the period range 8 to 165 hours including the full loading effect, Geophys. Res. Lett.,, 34, L05606, doi:10.1029/2006GL028870.

Müller, M. (2008), Synthesis of forced oscillations, part I: Tidal dynamics and the influence of the loading and self-attraction effect, Ocean Modell., 20, 207-222, doi:10.1016/j.ocemod.2007.09.001.

Müller, M. (2009), A Large Spectrum of Free Oscillations of the World Ocean Including the Full Ocean Loading and Self-Attraction Effects, Hamburg Stud. Marit. Aff., vol. 14, Springer, Berlin.

Munk, W. H., and D. E. Cartwright (1966), Tidal spectroscopy and prediction, Philos. Trans. R. Soc. Lond.on A, 259, 533-581.

Peltier, W. R. (2004), Global glacial isostasy and the surface of the ice-age Earth: The ICE-5G(VM2) model and GRACE, Ann. Rev. Earth Planet Sci., 32, 111-149.

Platzman, G. W. (1984), Normal modes of the world ocean. Part IV: Synthesis of diurnal and semidiurnal tides, J. Phys. Oceanogr., 14, 1532-1550.

Ray, R. D. (1998), Ocean self-attraction and loading in numerical tidal models, Mar. Geod., 21, 181-192.

Ray, R. D. (1999), A global ocean tide model from Topex/Poseidon altimetry: GOT99.2, NASA Tech Memo, TM-209478, 1-58.

Ray, R. D. (2006), Secular changes of the $M_{2}$ tide in the Gulf of Maine, Cont. Shelf Res., 26, 422-427.

Ray, R. D. (2009), Secular changes in the solar semidiurnal tide of the western North Atlantic Ocean, Geophys. Res. Lett., 36, L19601, doi:10.1029/2009GL040217.

Stepanov, V. N., and C. W. Hughes (2004), Parameterization of ocean selfattraction and loading in numerical models of the ocean circulation, $J$. Geophys. Res., 109, C03037, doi:10.1029/2003JC002034.

Thomas, M., J. Sündermann, and E. Maier-Reimer (2001), Consideration of ocean tides in an OGCM and impacts on subseasonal to decadal polar motion excitation, Geophys. Res. Lett., 28, 2457-2460.

Woodworth, P. L. (2010), A survey of recent changes in the main components of the ocean tide, Cont. Shelf Res., 30, 1680-1691.

Woodworth, P. L., S. M. Shaw, and D. L. Blackman (1991), Secular trends in mean tidal range around the British Isles and along the adjacent European coastline, Geophys. J. Int., 104, 593-609.

Zahel, W. (1980), Mathematical modelling of global interaction between ocean tides and Earth tides, Phys. Earth Planet. Inter., 21, 202-217.

Zahel, W., and M. Müller (2005), The computation of the free barotropic oscillations of a global ocean model including friction and loading effects, Ocean Dyn., 55, 137-161, doi:10.1007/s10236-005-0029-y.

B. K. Arbic, Department of Geological Sciences, University of Michigan, Ann Arbor, MI 48109, USA. (arbic@umich.edu)

J. X. Mitrovica, Department of Earth and Planetary Sciences, Harvard University, Cambridge, MA 02138, USA. (jxm@eps.harvard.edu)

M. Müller, School of Earth and Ocean Sciences, University of Victoria, PO Box 1700,Victoria, BC V8W 2Y2, Canada. (mmueller@uvic.ca) 